\title{
Seasonal Thermal Sensation Vote - An indicator for long-term energy performance of dwellings with no HVAC systems
}

\author{
D. Cóstola ${ }^{1}$, G. Carreira ${ }^{2}$, L. O. Fernandes ${ }^{3}$, L. Labaki ${ }^{2}$ \\ 1 - University of Strathclyde, Scotland, United Kingdom \\ 2 - State University of Campinas - UNICAMP, Brazil \\ 3 - Faculdade Meridional - IMED, Brazil
}

\begin{abstract}
Dwellings with no heating, ventilation and air conditioning (HVAC) systems are commonly found in many countries. The long-term thermal performance of these buildings can be assessed based on hourly data of occupant thermal discomfort integrated over the required timespan (e.g. total degree hours of discomfort per year). This approach can be easily applied when simulation is adopted in the assessment, but field studies using this approach are rare as they would require complex, costly and long measurement/survey campaigns. This paper addresses the challenges on conducting field studies on long-term thermal performance of dwellings with no HVAC system by introducing a novel performance indicator: the Seasonal Thermal Sensation Vote (S-TSV). S-TSV adopts the standard 7-point thermal sensation scale and is based on the perceived overall thermal sensation recalled by the user of the building for specific seasons and times of day. The new performance indicator is not intended to replace existing ones, but to complement them in the understanding of the complex thermal performance processes taking place in buildings with no HVAC. S-TSV was applied in a field study targeting a small sample of dwellings in Brazil. Results demonstrate the capabilities of S-TSV to describe trends in buildings performance in this sample. STSV also assisted on the identification of relationships between such performance and some independent variables addressed in this field study (e.g. windows operation, footwear and income), considering a threshold of p-values < 0.05 on the chi-square statistic test.
\end{abstract}

Keywords: energy performance; long-term performance; performance indicator; naturally ventilated buildings; thermal comfort. 
Thermal performance of dwellings is an important consideration for current energy efficiency policies [1-12].

3 Energy policy for the built environment is usually focused on reducing the energy used for space conditioning, ventilation, lighting and hot water by setting minimum requirements for the performance of equipment and building components [1,13-15]. Regarding space conditioning, this approach has been reasonably successful in buildings with heating, ventilation and air conditioning (HVAC) systems, which are commonly found in developed countries, particularly in heating dominated climates $[1,16,17]$. However, a large proportion of world's population lives in developing countries located in tropical regions, where the use of HVAC in buildings is not yet widespread due to economic, technical and/or cultural constraints [18-29]. Consequently, these countries have not faced the need for energy policy focused on space conditioning. There is evidence that this scenario is changing with increasing penetration of HVAC in these markets [30,31]. The increase in HVAC adoption poses a significant challenge for the energy security and greenhouse emission targets of developing countries [32-34]. Some of these countries are, therefore, implementing energy policies focused on buildings without HVAC, in an attempt to improve the thermal comfort in these buildings and consequentially reduce the adoption of HVAC systems [35,36]. This paper addresses the need for metrics to support field studies on the thermal performance of buildings without HVAC, assisting the development and implementation of energy policy for these buildings. By definition, these policies are not directly related to energy usage, but rather related to thermal comfort levels in buildings (as no energy is used for space conditioning). The expression "thermal comfort policy" is not common in the literature, hence the terms building performance and energy policy are adopted throughout this paper to refer to issues related to both the energy consumption in buildings with HVAC and to the levels of comfort achieved in buildings without HVAC.

In buildings with HVAC, energy performance can be directly related to the annual predicted or measured energy consumption (e.g. [37]). This approach, however, is not applicable for dwellings without HVAC. In these cases, performance metrics have been proposed to describe the energy performance based on the level of thermal comfort provided by the dwelling. Thermal comfort assessment of buildings without HVAC is often conducted using dynamic energy simulation in order to obtain hourly values of temperature and other relevant variables for each room [38]. The long-term (annual) performance is then calculated using a frequency-based approach [38], e.g. by the sum of hours of thermal discomfort according to a given thermal comfort model [39-42], preferably using an adaptive thermal comfort model that is suitable for buildings with no HVAC. Such frequency-based approach using simulation results has several advantages, as it: (a) provides well-defined metrics for long-term building performance, (b) can be used to calculate performance at specific times and locations within the building, and (c) supports detailed hourly analysis of building performance. A detailed review and comparison of frequency-based long-term performance approaches is provided in Ref. [43,44], where it is clear that all existing methods, even the simplest ones, require high-frequency data collection over large periods of time. While the simulation of long-term performance using a frequency-based approach is reasonably straightforward, field studies measuring performance in a similar fashion are cumbersome. Frequency-based assessments would require complex measurements, collecting high temporal resolution data (e.g. hourly) of several variables (air temperature, mean radiant temperature, air speed, relative humidity) in several rooms (or points within a room) throughout the entire year (e.g. [45]) combined with detailed surveys on occupants behaviour and thermal sensation. In face of these complex requirements, field data on long-term frequency-based performance is rarely available for building without HVAC.

40 The importance of empirical assessment of energy performance of existing buildings is acknowledged in the literature [46] and the state-of-the-art approach (i.e. frequency-based over long timespans) hinders field studies on 
the performance of buildings without HVAC system. There is a need for new approaches to support such field studies, contributing to the understanding of long-term energy performance of these buildings.

The investigation of long-term performance energy performance of buildings with no HVAC has many similarities with research conducted in the field of Post-Occupancy Evaluation (POE). POE have been used to evaluate a wide range of buildings, from so-called green buildings [47,48] to housing [49-51], education [52-54] and public buildings [55,56]. POE has also being included in frameworks aiming at reducing the building performance gap [57,58] and new POE techniques have been developed to tackle a number of issues in the indoor environment [59-65]. However, such developments have not tackled the need for robust metrics for energy performance in buildings with no HVAC. These can be exemplified by two important POE references, the BUS survey and the Energy Follow-Up Survey (EFUS) survey. The BUS survey, for example, asks subjects to rate the "temperature in winter" and "temperature in summer" in a scale from "uncomfortable" to "comfortable". This approach reduces the thermal experience to a single variable, forcing the subject to evaluate the performance of the building/space in terms of temperatures when comfort is the result of multiple factors (e.g. mean radiant temperature, humidity, air velocity and direction, turbulence level, radiant asymmetry, air temperature vertical stratification, floor temperature [41]). Besides, the BUS survey is proprietary and the methodology and questionnaire are not publicly available [66]). An analysis of the Energy Follow-Up Survey (EFUS) 2011 [67] shows how semantics play a significant role in data collection and can hinder the use of some POE results in other contexts. In EFUS, subjects were asked to if they were normally able to keep comfortably warm in their living room. EFUS adopts the word "warm" rather than "neutral" as the reference for comfort, which hinders the comparison of EFUS results with other similar studies in the area of thermal comfort. Such uniformity in methodology is essential to this field of study, as demonstrated by the powerful results obtained by RP-844 where the comparison of multiple previous studies created ground to the modification of several standards [40,41].

In this paper, we explore an alternative approach for performance assessment focused on the overall perception by occupants regarding the thermal comfort experienced in the building, instead of relying on detailed highfrequency measurements. This route has been explored, to a certain extent, on the ASHRAE RP-844 database [68], acknowledging previous studies where occupants' behaviour was assessed using questions such as: "How often do you exercise the option of opening windows (never, rarely, sometimes, often or always)?”. This approach is fundamentally different from data collection for frequency-based analysis. Data collection based on the overall perception of occupants facilitates performance assessments regarding large timespans as it is based on questions that can target any element of interest in space and time. Questions using the overall perception approach pose an alternative to frequency-based data collection (as exemplified in some cases in the ASHRAE RP-844 database). Questions based on the overall perception approach have been used in a limited number of previous studies assessing thermal comfort in particular buildings [69-71]. These studies, however, made no attempt to define an indicator suited for this approach. As such, these studies achieved a degree of impact regarding the results presented, but no impact regarding the methodological approach used for data collection. The current lack of a framework for surveys based on overall perception constrains their usage, as researchers may be unable to judge the reliability of the results. The research reported in this paper provides such a framework and demonstrates that this approach can offer a valid contribution to the understanding of the performance of buildings with no HVAC.

This paper proposes and tests a novel performance indicator of the long-term energy performance of buildings with no HVAC, tailored for assessments based on the overall perception approach. This performance indicator is described in Section 2. Sections 3 and 4 are dedicated to a field study, designed to test the capabilities of this 
indicator by investigating the thermal performance of a sample of dwellings with no HVAC in Brazil. Section 5 discusses the implications of S-TSV to futures studies in this research field. Section 6 summarizes the main findings of this paper.

\section{Seasonal Thermal Sensation Vote}

The metric proposed in this paper combines the proven strength of the 7-point scale for Thermal Sensation Vote (TSV) [39] with the need for a clear metric to represent the thermal performance of dwellings with no HVAC over long timespans. This new metric, the Seasonal Thermal Sensation Vote (S-TSV), is defined as the perceived overall thermal sensation in a building, as recalled by a user considering a particular long-term timeframe (e.g. season). The key advantage of S-TSV is the ability to query users about their recollection of sensations from previous seasons rather than only addressing the current thermal comfort state of the subject at the time of the survey. By this approach, it is possible to collect data about various periods of the year in a single, brief interview. There is no doubt this approach has lower resolution when compared to high-frequency data collected using measurements or interviews. Therefore, S-TSV is suitable for cases where trade-offs in resolution are acceptable and frequency-based thermal comfort assessments are not feasible due to time, cost or logistic constraints. One should keep in mind that recollected sensations have an inherent uncertainty, as people's memory is affected by a number of factors [72-74] (please see a brief discussion about this issue in Section 5).

In spite of using a thermal comfort scale, S-TSV should not be mistaken by a thermal comfort indicator. There is a large body of knowledge on experimental studies to assess thermal comfort that show some degree of resemblance with the collection of S-TSV, ranging from classic experiments and surveys carried out in the last century [75-81] to recent research activity considering both: a) a variety of building types/environments (e.g., [82$95]$ and b) controlled environments in the laboratory $[75,78,87]$. Such extensive research on thermal comfort aims at correlating environmental variables and thermal sensation votes. S-TSV, on the other hand, is designed to characterize the building itself, with no attempt to address the interaction of environmental variables and human thermal response. S-TSV is therefore not a thermal comfort indicator, but a building performance indicator.

S-TSV can, in principle, be used to assess perceived building performance for different timescales and seasons. However, for simplicity S-TSV may be applied only for summer and winter periods. Summer and winter represent extreme situations that may drive measures to mitigate potential thermal comfort issues (e.g. acquisition of HVAC and upgrades on building envelope). Such measures are central elements of energy policies for buildings, hence STSV is collected in this research only for summer and winter seasons. Mid-season can also be addressed by future studies using S-TSV, as changes in building operation and higher thermal adaptation may occurs in these seasons.

An additional level of detail may be added to S-TSV by separating data collection for day and night periods. Thermal performance may vary dramatically over the course of the day due to the interaction between thermal mass of buildings and the diurnal thermal amplitude of the climate. The separation of S-TSV for day and night times gives the interviewee a more effective means to express their perception of the building performance under different conditions. In total, four values of S-TSV are used in this paper to describe the long-term (annual) energy performance of buildings with no HVAC:

- $\quad$ S-TSV for summer days,

- S-TSV for summer nights,

- S-TSV for winter days,

- S-TSV for winter nights. 
Questions used to collect S-TSV data follow the pattern in this example: "Using this scale (the 7-point scale was shown to the interviewee), how would you classify the thermal sensation in your dwelling, as a whole, during daytime in summer?".

Using four straightforward questions on S-TSV, it is possible to obtain an overall understanding of a building ability to provide thermal comfort (from the user point of view). This offers means for a high-level characterization of the energy performance of the dwelling (or of the building stock, in cases where data on S-STV is collected for an adequate sample of buildings). As stated before, this new performance indicator is not meant to replace existing ones, but to complement current approaches in the understanding of energy performance of buildings with no HVAC. In the following sections, the capabilities of S-TSV are demonstrated in a field study.

\section{Methodology of the field study}

\section{1}

\subsection{Location and climate}

The field study was conducted in Brazil, a country where a large amount of dwellings have no HVAC system [9699]. The area addressed in this study is the upper middle-class neighbourhood (Barão Geraldo) in the city of Campinas (in the southeast region of Brazil). The neighbourhood addressed in the field study, depicted in Figure 1, is strictly residential, with single-family detached dwellings in large plots (around $10 \mathrm{~m} \times 25 \mathrm{~m}$ ), many of them featuring private swimming pools and a considerable amount of vegetation. Campinas is one of the wealthiest metropolitan areas in the country, with 2.2 million inhabitants. This city is located in the also wealthy state of São Paulo, therefore energy performance results are expected to reflect the best practice in construction in the country.

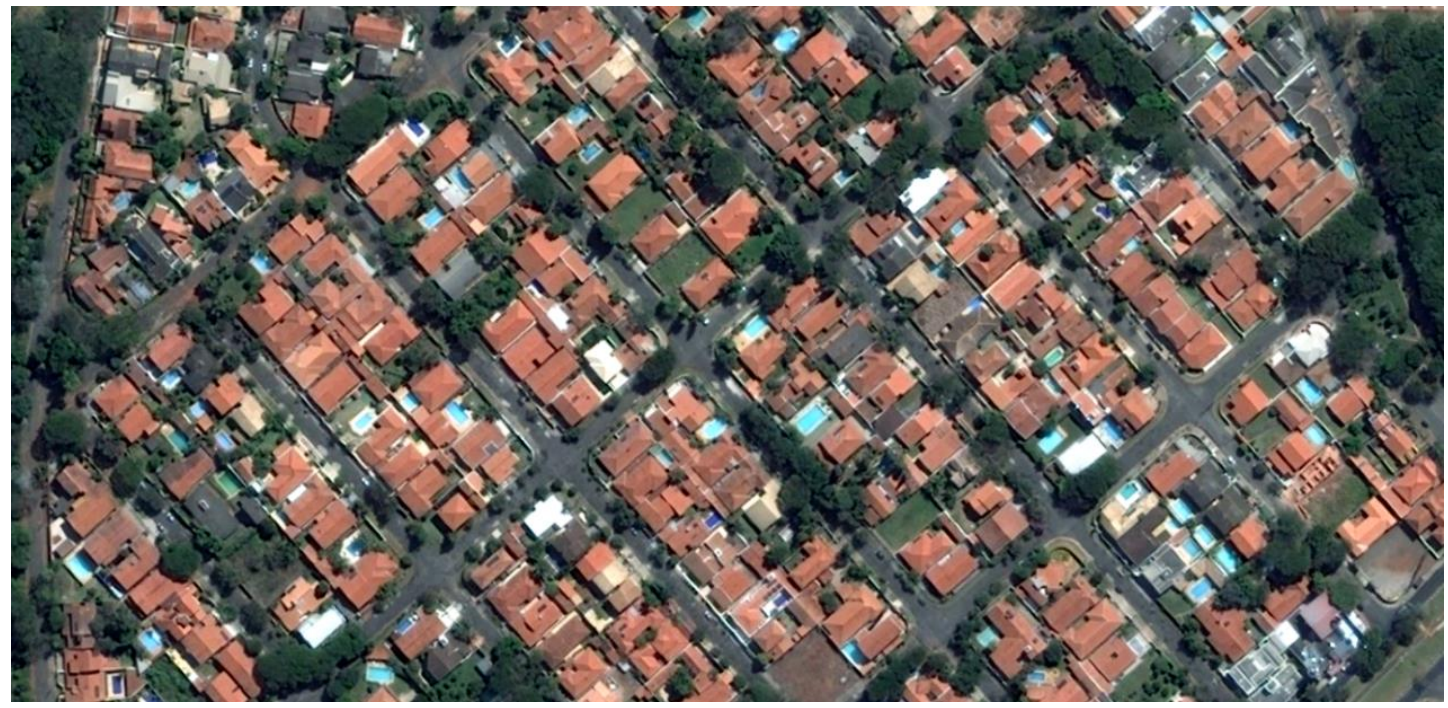

Figure 1. Aerial image of the area covered in the field study, a upper middle-class neighbourhood (Barão Geraldo) in the city of Campinas, Brazil [100].

In order to put in to context the results of this field study, a brief summary of climatic conditions in Campinas is provided below. The city of Campinas has a hot dry climate (Köppen- Geiger classification: humid subtropical climate - Cfa), exemplified by the outdoor air temperature variation during the month of January depicted in Figure 2 (summer in the Southern Hemisphere). Temperatures often reach $30^{\circ} \mathrm{C}$ during summer days, but the climate is not extreme. This can be observed by comparing outdoor temperatures against the adaptive thermal comfort range prescribed by EN 15251 [41] category III, marked in grey in Figure 2. Buildings that provide conditions similar to the outdoor climate will easily deliver thermal comfort during summer for the majority of the time. Proper passive design is facilitated in this region by the dry summer climate which is responsible for considerable temperature 
drops in the evening, with a minimum often below $20^{\circ} \mathrm{C}$ and daily amplitudes above $10^{\circ} \mathrm{C}$. This pattern indicates

2 potential for night ventilation for passive cooling further improving thermal comfort during daytime.

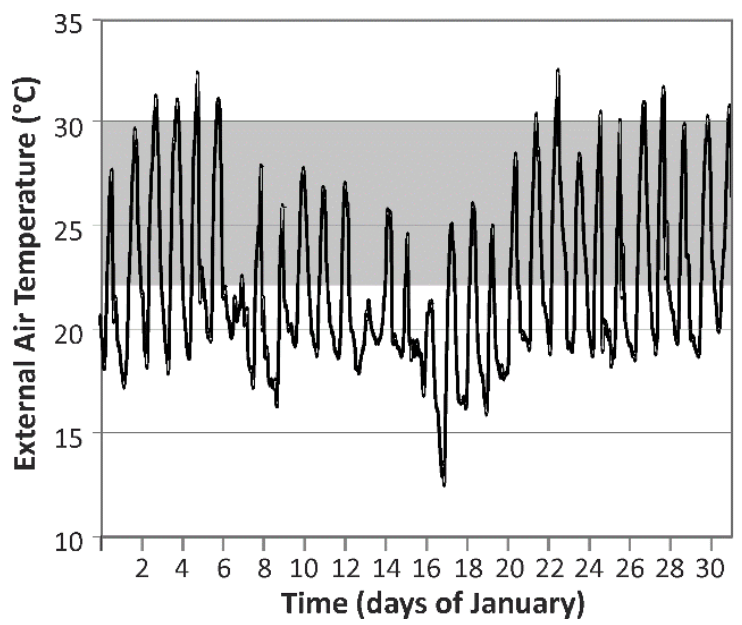

Figure 2. Sample of outdoor air temperature in summer days in Campinas, Brazil (data from [101]). Area in grey shows comfort zone Category III on EN 15251.

Regarding the winter season, Figure 3 shows two sets of outdoor air temperature measurements where the minimum temperature reaches low levels $\left(5^{\circ} \mathrm{C}\right)$ indicating a potential for indoor thermal discomfort. However, daily amplitudes in Figure 3 indicate the availability of sun and warm air during the daytime for passive heating, which combined with building thermal mass can potentially modulate temperature swings improving thermal comfort in dwellings in this region. Adequate thermal insulation levels and infiltration control could facilitate adequate thermal comfort during winter.
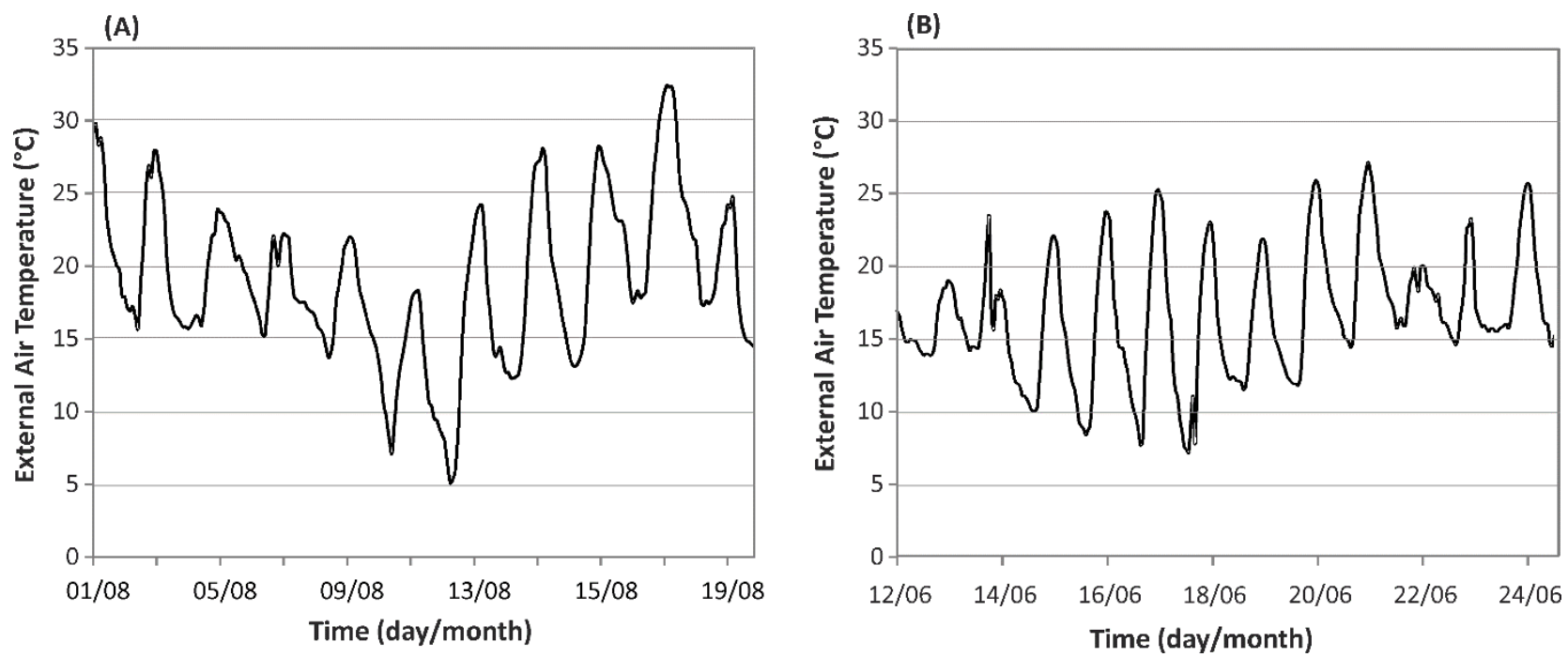

Figure 3. Sample of outdoor air temperature in winter days in Campinas, Brazil:

(A) period with annual minimum temperature and (B) temperature during the winter solstice (data from [101]).

\subsection{Sample and S-TSV data collection}

A total of 42 dwellings were investigated in the survey, being all located in the same neighbourhood, sharing a similar floor area, plot size, construction techniques, socio-economic constraints and climatic conditions. Interviewees were well-distributed in gender (47\% male and 53\% female), with ages ranging from 18 to 65 years old. Interviews were conducted in the spring of 2014, always during daytime, and in the living room at each dwelling. The survey comprised closed questions, asked verbally by the interviewer (who took note of answers and 
also of the interviewees' reactions and comments during the interview). The interview was divided into three parts:

2 (a) an initial question regarding the thermal sensation vote at the moment of the interview, followed by (b) questions on S-TSV for the four defined periods (winter/summer, day/night), and (c) a final round of questions on socio, economic, and behavioural independent variables which are described in Section 3.3. The initial question addressing the thermal sensation vote at the moment of the interview was used as means to introduce the 7-points thermal sensation scale. A small pilot study prior to the main survey indicated that the understanding of the 7-point scale was improved by asking for the TSV at the time of the interview. The scale was introduced to interviewees at the beginning of the interview. Only the description of each vote was presented (i.e. "hot", "warm”, etc.) leaving out the corresponding numerical value (i.e. " $+3 ", "+2 "$, etc.), as the values were identified as a distraction by

10 interviewees in the pilot study. Interviewers were instructed to note down any remarks by interviewees regarding 11 the understanding of the questions. Interviewees did not report problems on understanding or answering the proposed questions. The next section describes additional questions addressing socio-economical and behavioural variables.

\subsection{Independent variables}

15 Independent variables have an important role in energy performance assessments, as they assist in the identification of potential trends and biases related to socio-economic, physiological, psychological and behavioural aspects. Results of four independent variables are presented in this paper: windows operation, footwear, income and overall satisfaction with the dwelling. The data collection and results discussion for each of these variables alone is of sufficient interest to constitute a set of independent studies, requiring an account of the current literature for each topic. This section briefly addresses previous studies for each identified variable, allowing the added value of the new data to be assessed against the existing knowledge base. Independent variables were collected in this study as means to demonstrate the effectiveness of the S-TSV approach in identifying elements that play a role in thermal comfort and building performance. As such, results for each independent variable must be seen as exploratory findings using a new methodology. The data collection process for these variables is discussed in the following paragraphs.

Window operation is an active research topic, with studies ranging from the identification of driving factors to the development of stochastic models to predict user behaviour [102,103]. Studies reported in the literature often rely on detailed accounts of window operation over considerably long timespans, using diaries filled by users and/or sensors to monitor window state and other variables [104-110]. As already discussed regarding thermal comfort studies, this sort of field work for window operation monitoring is rather complex and impractical to be applied in a large sample of buildings. Therefore, the same approach adopted on the collection of S-TSV was applied to questions on building operation and user behaviour. Interviewees were invited to recall, at the time of the interview, the overall pattern regarding the topic addressed in the question (e.g. window opening schedule) rather than requesting users to record in detail their activities over time. This approach facilitates data collection on window operation and maintain the same level of resolution for all variables in this study. For each season (summer and winter), users were asked if windows of the house, in general, would be likely to stay opened or closed in 4 periods of the day: morning, afternoon, evening and night. Separating data on window operation to cover time slots during the day facilitates the understanding of ventilative cooling usage in a city with high thermal amplitude like

39 Campinas, potentially casting further light on the building performance results obtained using S-TSV. Readers 
should keep in mind that recollection of actions (e.g. window opening schedule) and actual behaviour may differ (a relevant topic for future investigation).

The second feature investigated as an independent variable is the use of footwear at home and its potential role in thermal sensation. The clothing worn at home has a higher level of flexibility than experienced in other types of buildings. In some hot countries, it is common practice to be barefoot at home, referred to in the literature as one type of endemic adaptation [111]. This is particularly valid for dwellings using so-called "cold flooring", i.e. floor finishing with high thermal diffusivity such as stones, ceramic tiles and concrete (as opposed to wooden floors and carpets) [112]. Being barefoot may improve thermal comfort in warm climates by increasing heat conduction losses to the floor (a classic problem in heat transfer textbooks, e.g. Ref. [113] - page 273 and Ref. [114] - page 315). The existing literature shows the important role of footwear in foot comfort [115,116] and the impact of heat losses from feet in the overall thermal response of the human body [117,118]. However, current practice in thermal comfort models for the build environment does not consider the thermal response of different body parts, and is therefore insensitive to variations in footwear. In the PMV model, for example, insulation values for shoes and socks are quite low (around $0.05 \mathrm{clo}$ ), having a correspondingly minor impact on the results. The adaptive model in EN 15251 does not differentiate users by footwear [41]. ISO/TS 13732-2 provides recommended floor temperatures for a variety of situations (considering footwear), but does not address the effect of footwear and floor temperatures on the overall thermal sensation calculated using PMV or the adaptive models [119]. Most laboratory experiments about thermal comfort do not address footwear variations, with subjects in standard footwear or with feet not in contact with the floor $[84,117,120,121]$, in order to minimise the impact of this variable in the analysis. High-resolution experiments and models of heat transfer focused only on the feet also tend to assume standard footwear or feet not being in contact with the floor $[122,123]$. A steady-state regime is a common assumption in experimental laboratory studies of heat transfer focused only on the feet [124], although a growing interest in transient experiments and models for the whole body has been reported in the literature $[87,123,125]$. Whole-body transient high-resolution thermal comfort models can potentially be applied to investigate the impact of footwear on the overall thermal comfort response, such as the Berkeley Comfort Model [126,127], the model by Fiala [128-131] and variations of the Fiala model e.g. ThermoSEM [132-134]. However, these models are complex, computationally intensive, not available as open-source software, and consequently they are rarely used in practice for built environment studies. Thermal comfort models are the basis for frequency-based assessment of long-term performance of buildings with no HVAC, therefore any limitations of these models have a direct impact on the assessment. In light of the identified role of footwear in thermal comfort, an additional control question was added in the present study to investigate a possible relationship between this adaptive measure and S-TSV responses. As for the other independent variables, interviewees were asked if, in each season (summer/winter), they would likely be: always barefoot, frequently in footwear or always in footwear at home.

The third independent variable investigated in this research was the income of interviewees. The survey was conducted in a wealthy neighbourhood, therefore the variation in income will not cover the whole range found in the country. Nevertheless, this variable can indicate if, even in a wealthy area, income plays a significant role in the energy performance of dwellings with no HVAC system. The relation between building energy performance and income is well documented for heating dominated countries, where fuel poverty is a major issue [135-141]. However, research on this relation has not been extensively reported in the literature regarding dwellings with no HVAC in cooling dominated countries. 
The fourth and last independent variable investigated in this research is the overall satisfaction with the dwelling and its relation with S-TSV. There is a considerable body of research on residential satisfaction related to other elements, such as urban/building features and design process (e.g. user participation in the design process) [142151]. In the present study, this variable can indicate how increasing levels of thermal discomfort affect the overall satisfaction with the dwelling. Such data can potentially cast light on the amount of thermal discomfort tolerated by users before their overall satisfaction with the dwelling is compromised. Knowledge of thermal discomfort thresholds could, in principle, be used in the future to define acceptable levels of thermal discomfort in dwellings with no HVAC for a given population and climate.

The relationship between these independent variables and the performance of dwellings with no HVAC has not 10 been reported in the literature, as such studies would be cumbersome using the current practice for thermal comfort 11 surveys. In order to assure the validity of results regarding these independent variables, the statistical significance was assessed whenever applicable using the chi-square statistic test, based on a p-value threshold of 0.05. This test 13 is used, for example, in the pharmaceutical industry to assess the efficacy of a new treatment, by analysing if results 14 of the group taking the new drug are significantly different from the results of the control group taking a placebo.

15 Here, the chi-square test provides a means to compare the S-TSV results of two groups (e.g. people in footwear 16 versus people in barefoot). The test assesses if variations in results are statistically significant $(p$-value $<0.05$, i.e. 17 differences in footwear are associated with different S-TSV results) or not ( $\mathrm{p}$-value $>0.05$, i.e. differences in 18 footwear plays no noticeable role in S-TSV responses). The next section describes results found in this survey, 19 focusing first on the S-TSV results for the whole sample of buildings, followed by a discussion of the results with specific reference to the independent variables.

\section{Results of the field study}

\subsection{Overall energy performance of buildings in the sample}

In this section, S-TSV results for the whole sample were analysed to characterise the energy performance for this group of dwellings. This analysis addresses a small sample of dwellings, but the same approach could be adopted to describe the performance of a large group of buildings or the entire building stock of a country.

Figure 4 shows relative frequency results of S-TSV for day and night time during summer and winter. Results are coloured using a scheme that facilitates the differentiation of votes usually associated with acceptable conditions (neutral in green, slightly warm in light yellow and slightly cold in light blue) from votes related to significant discomfort by heat (warm and hot in orange and red, respectively) and by cold (cool and cold votes, in dark blue and purple). 


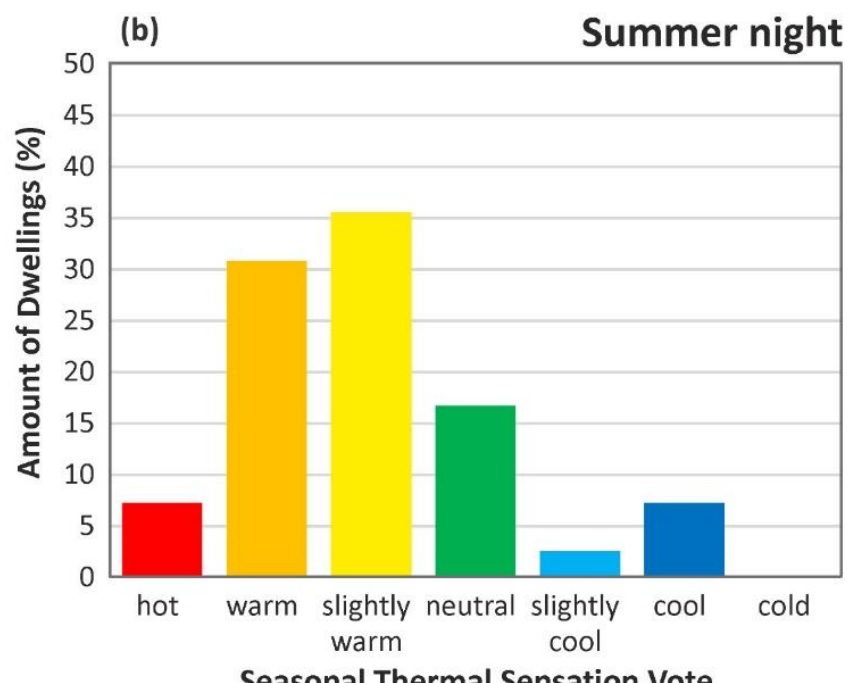

Seasonal Thermal Sensation Vote

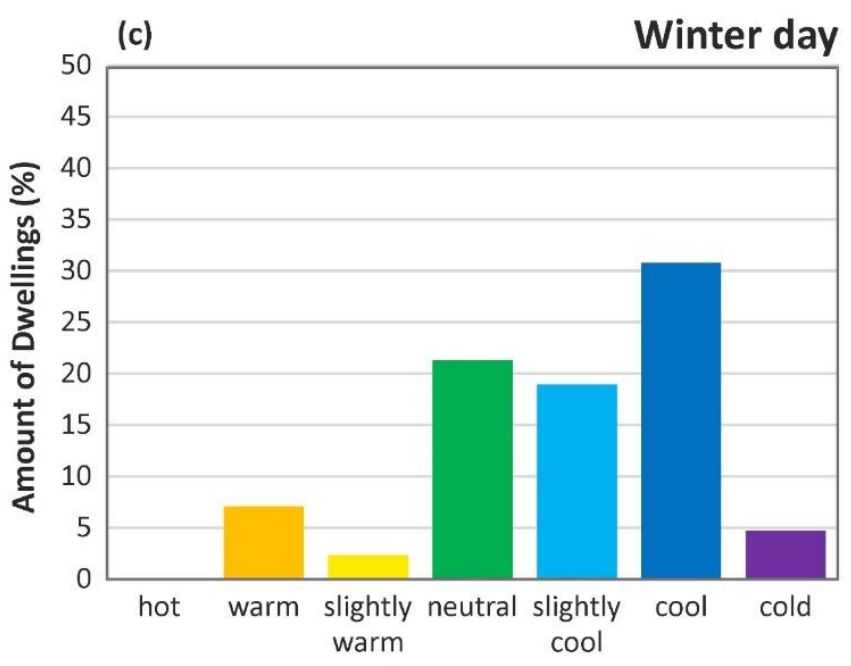

Seasonal Thermal Sensation Vote

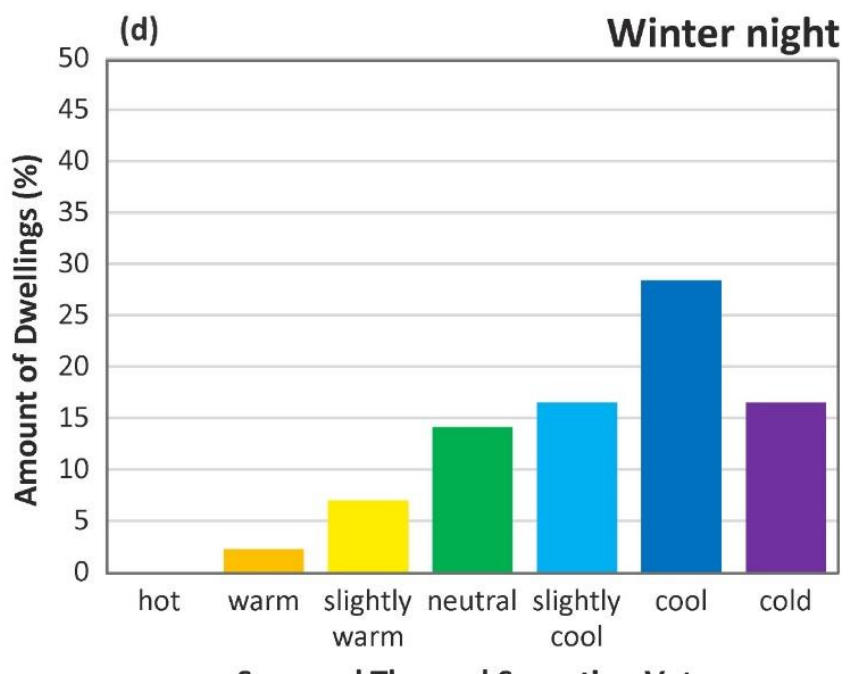

Figure 4. Seasonal thermal sensation votes (S-TSV) for a sample of dwellings in Campinas, Brazil.

Results in Figure 4a show high levels of discomfort by heat during summer days, with approximately 2 out of 3 dwellings reported as warm or hot. There is also considerable discomfort during summer nights (Figure 4b,

3 approximately 1 out of 3 dwellings). Possible reasons for such performance are addressed in Section 4.2, considering 4 data for the independent variables collected in this survey. However, prior to considering the reasons for this 5 performance, it is clear that a large proportion of these buildings do not provide a good thermal environment in 6 summer. Results of this nature are in line with the growth in recent years in sales of air-conditioning equipment as 7 a result of a decade of economic prosperity and increasing living standards in Brazil [152] (now interrupted by a 8 financial and political crises).

9 Results in Figure 4c and 4d also indicate that uncomfortable conditions are widespread during the winter, where 101 out of 3 dwellings during daytime, and approximately half of the dwellings during night time are considered cool 11 or cold. These are surprising results considering the typically mild winters in this region. Potential reasons behind 12 this poor performance in the winter period are addressed in Section 4.3. One could predict that such poor 13 performance would be found in informal settlements typical of developing economies. However, the dwellings in 14 this sample are located in a wealthy neighbourhood and the presented results possibly indicate alarming levels of 
discomfort in Brazilian dwellings, reaching even those in upper social levels. Section 4.4 includes further discussion on the role of income in the results in Figure 4.

For both seasons and times of day analysed, between 15 and $20 \%$ of the dwellings have responses that suggest thermal neutrality, which indicates that a proportion of existing building features and user behaviours are capable of providing good performance for the climate of this region. Identifying cases with good performance is essential in order to improve the overall performance of the building stock. Lessons from such cases may be replicated in other buildings, as all dwellings share the similar key features.

In a few cases, the performance found in this survey is opposite to the one expected (i.e. slightly cool in the summer or slightly warm in the winter). These cases must be further investigated in future studies to identify construction and operation features of these buildings, but also to assess the possibility of an unusual thermal response from these particular users due to personal habits or psychological/physiological particularities. The role of personal habits in thermal response is briefly discussed in Section 4.2 based on the results of an appropriate independent variable (footwear preferences).

Results in Figure 4 were obtained based on a small sample and must be reassessed in future studies using larger samples of the building stock. However, these results show the usefulness of S-TSV as a performance indicator for groups of dwellings with no HVAC. A classic performance assessment using thermal comfort measurements would require a large apparatus even for this small sample of dwellings: (a) instrumentation to cover each room per house, (b) long measurement campaigns using detailed measurement protocols, (c) measures to minimize the disturbances in household routine (particularly when globe thermometers are placed centrally within rooms) and (d) detailed logbooks of building operation and thermal sensation votes. The value of such detailed measurement campaigns is obviously enormous, but the cost and complexity are often prohibitive. In contrast, the use of only four questions in the S-TSV approach was capable of providing an affordable and clear high-level assessment on the thermal performance of these dwellings. This information can be used to define priority cases for in-depth detailed thermal comfort experiments and it can also be directly used to support the development of policies to improve the thermal performance of dwellings with no HVAC. In the next three sections (4.2, 4.3 and 4.4), results from Figure 4 are further scrutinized in light of results of the identified independent variables.

\subsection{Analysis of energy performance during summer}

Results in Figure 4 indicate that most buildings in this sample may fail to a large extent in providing shelter from the environment, delivering a worse performance than one would experience outdoor during daytime in a shaded area (as shown in Figure 2). Proper design and operation could greatly improve building performance and some recommendations in this direction are provided in the following paragraphs.

The considerable thermal amplitude and moderate temperatures during the night (Figure 2) make buildings with high thermal mass in Campinas ideal candidates for passive cooling using night ventilation, in conjunction with selective ventilation and solar control during the day as in [153,154]. However, evidence suggests that buildings are operated in the opposite way, as shown in Figure 5. This figure, which shows data for one of the control questions used in the survey, indicates the number of dwellings where windows are likely to be open in each period of the day during the summer.

According to the data in Figure 5, windows are usually open during the day whereas the external conditions (high solar radiation and air temperatures) would suggest limiting solar gains and ventilation to the minimum required for acceptable indoor air quality. During the night, windows are closed in almost all buildings, and therefore 
not making use of low outdoor air temperatures to cool down the building using natural ventilation. In spite of a

2 considerable body of research in the field of window operation by building users, the behaviour shown in Figure 5

3 in association with the thermal discomfort reported in Figure 4 has not being identified before to the knowledge of

4 the authors. This operation pattern may be in part responsible for the poor performance during summer shown in

5 Figure 4, particularly considering the relatively high thermal mass of constructions often found in this region. There

6 is consensus among experts on the importance of natural ventilation in Brazilian dwellings, but the data in Figure 5

7 may indicate that the level of awareness among householders is insufficient to improve building performance.

8 Poorly timed ventilation may be more harmful than beneficial for building performance, contradicting the common

9 belief that ventilation is always positive to building performance in this particular climate. Critical barriers to natural

10 ventilation during the night, such as burglary, mosquitoes, noise, privacy, rain and also undesired sunlight after

11 dawn may be possible reasons for such apparently counterintuitive behaviour [155]. Findings regarding window operation demonstrate how the combination of data on S-TSV (e.g. Figure 4) and operational data (e.g. Figure 5)

13 can be used to investigate performance issues in a cost-effective manner. Other factors influencing the thermal 14 performance of buildings can also be investigated in combination with S-TSV data, such as the user adaptive 15 behaviour to improve thermal conditions illustrated in the next paragraph.

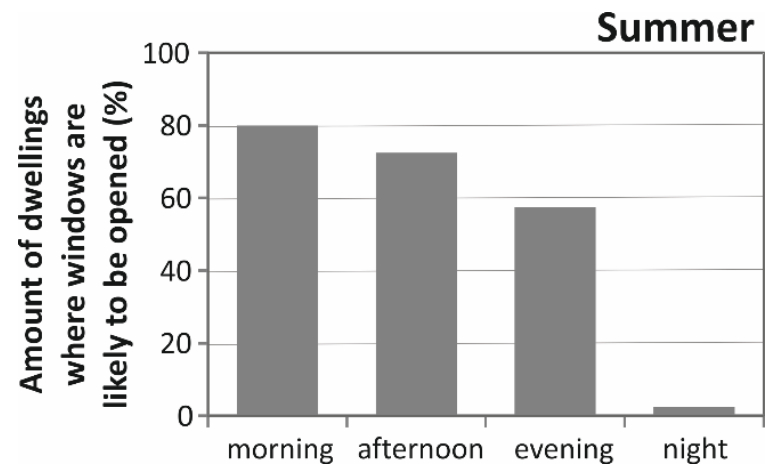

Figure 5. Windows operation during summer, as recalled by users during the survey in a sample of dwellings in Campinas, Brazil.

Results for usage of footwear at home indicate that approximately $60 \%$ of the interviewees in this study are always barefoot in their dwellings during summer days, while the other $40 \%$ always or frequently use footwear. Figure 6 shows data on S-TSV for summer days for these two groups of people (always barefoot; always/frequently in footwear). This figure shows an apparent trend of better thermal comfort among those always barefoot at home. The chi-square test demonstrates that these two groups have statistically significant differences in thermal responses $(\chi 2=6.88 ;$ p-value $=0.03)$.

Data in Figure 6 indicates that people who are barefoot at home in summer are twice as likely to be thermally satisfied (neutrality or slightly warm) than those in footwear. These results indicate that being barefoot (a relatively small and harmless change in behaviour) can potentially lead to a substantial improvement in occupant thermal comfort in warm climates. These results reinforce the identified importance of thermal adaptation on the achievement of adequate comfort levels reported in the literature [121,156-159], opening research fronts by reassessing known variables which may play a more relevant role in human thermal response than current models account for (as in Ref. [120]). This thermal adaptation measure requires some change in behaviour and social norms, however it is much less intrusive than other solutions reported in the literature (e.g. active cooling embedded in 
clothing [84]). Future studies may re-evaluate the role of footwear in thermal comfort models in face of this new

2 evidence investigating if the variation in perceived comfort remains significant in larger samples.

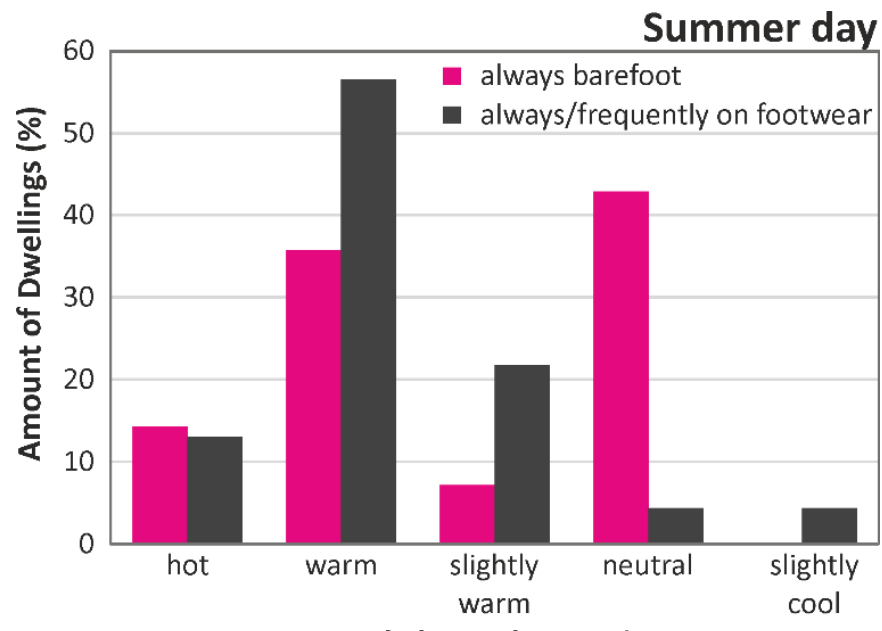

Seasonal Thermal Sensation Vote

Figure 6. Seasonal thermal sensation votes (S-TSV) in summer days as a function of footwear usually adopted by interviewees for a sample of dwellings in Campinas, Brazil.

\subsection{Analysis of energy performance during winter}

Thermal comfort data during the winter period (Figure 4) shows surprisingly poor performance considering this region has a very moderate winter. The potential for passive heating is apparently compromised in the dwellings addressed in this survey by sub-optimal windows operation (among other possible factors), as indicated by results in Figure 7. This figure shows data collected in this survey regarding window operation during the winter, similar to that presented in Section 4.2 for the summer period. Results show that most householders do not take advantage of maximum air temperatures in the afternoon to open windows and make use of passive heating. Most people open their windows in the morning, when the outdoor air temperature is still too low to promote passive heating. This window operation pattern seems to be driven by indoor air quality requirements, as fresh air in the beginning of the morning is used to dilute pollutants accumulated during the night when windows are closed. The lack of automation on window openings may also reduce the potential for window opening during times when occupants are at work and the house is often left unoccupied. Such counterintuitive ventilation pattern in tandem with the low insulation levels typical in this part of the country (U-values around $2 \mathrm{~W} / \mathrm{m}^{2} . \mathrm{K}$ for roofs, $3.6 \mathrm{~W} / \mathrm{m}^{2} . \mathrm{K}$ for walls and single glazing [160]) may be responsible for the poor energy performance during the winter period shown in Figure 4. Data on building performance and window operation provided in this research highlights the complex scenario faced by many developing countries in the provision of a healthy and energy efficient domestic environment for its citizens. S-TSV can assist them in the identification of cost-effective opportunities for performance improvement. 


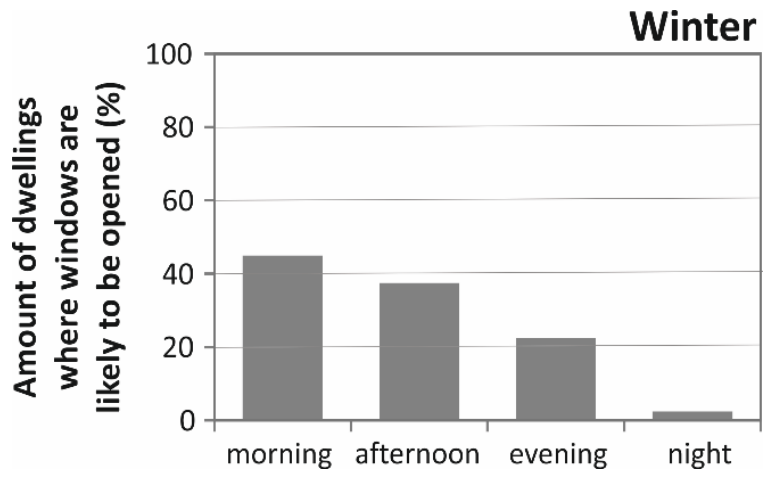

Figure 7. Windows operation during winter, as recalled by users during the survey in a sample of dwellings in Campinas, Brazil.

\subsection{Relation between energy performance and income}

Figure 8 shows thermal comfort data for daytime during summer, with interviewees divided into two groups based on income. Results indicate that higher income interviewees are twice as likely to live in a dwelling that provides thermal comfort (60\% in slightly warm, neutral or slightly cold state) than interviewees with a relatively lower income (30\% of interviewees in slightly warm, neutral or slightly cold state). This trend is not surprising as: (1) high income owners have the freedom, means and motivation to improve their dwellings to mitigate thermal comfort issues; (2) high income tenants may not have the freedom to modify their dwellings but they have the means to rent the most comfortable ones in a given region; and (3) interviewees in lower income ranges are subjected to poorer quality dwellings with lower thermal comfort potential, either as owners or as tenants. However, considering the high average income in this region, it is surprising to identify clear differences in performance between dwellings based solely on income. The chi-square test indicates that differences in performance found between the two income groups are statistically significant $(\chi 2=6.06$; $p$-value $=0.048)$. This result is in line with previous research in other countries indicating the relation between higher property value (i.e. higher income) and better energy performance [161]. As with other independent variables, such results must be further investigated in future studies and S-TSV has again demonstrated its usefulness on uncovering patterns in the performance of dwellings with no HVAC.

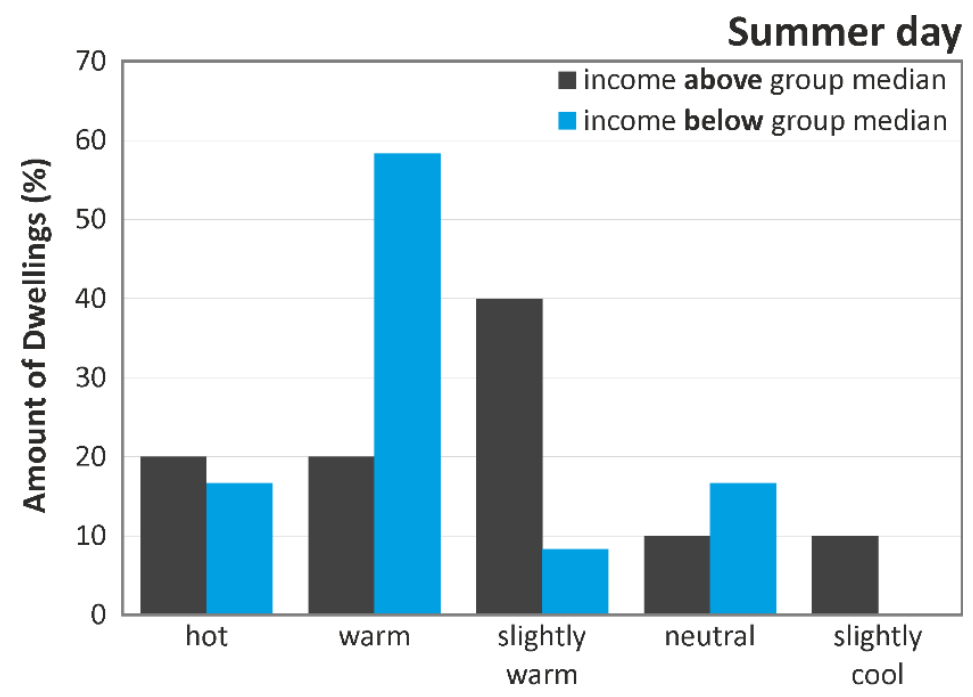

Seasonal Thermal Sensation Vote

Figure 8. Seasonal thermal sensation votes (S-TSV) for daytime in summer considering two groups with different income levels for a sample of dwellings in Campinas, Brazil. 
This section briefly discusses the relationship between users' expectations and their experience of the thermal performance in the built environment in Brazil. This expectation can be estimated based on the recently introduced performance-based regulation for Brazilian dwellings with no HVAC [162]. By this standard, new dwellings must provide indoor air temperature during winter at least $3^{\circ} \mathrm{C}$ above the minimum external temperature during winter [162]. Considering data on Figure 3, a dwelling in Campinas/Brazil with an indoor temperature as low as $8^{\circ} \mathrm{C}$ meets the new regulation, demonstrating a very low expectation of thermal performance for buildings in this developing country. Such low level of expectation may cast light on the social acceptance of the poor energy performance results shown in Figure 4. This social acceptance is supported by data collected in this survey addressing the overall satisfaction of interviewees regarding their dwellings (Figure 9). The vast majority of interviewees were satisfied or very satisfied with their dwellings; only 1 in 20 was slightly dissatisfied and no one reported to be very dissatisfied. Data in Figure 9 may indicate that thermal comfort is not a central requirement for a dwelling to be considered satisfactory (in the sample addressed in this study) and/or it may indicate that thermal discomfort is a common fact in this region and interviewees feel nothing can be done about it (other than installing HVAC systems). The size of the sample adopted in the present study hinders the analysis of correlations between level of satisfaction and S-TSV, as there is not enough data in each satisfaction level to support adequate statistic tests. The contrast between poor thermal performance and high overall satisfaction about the dwelling requires further investigation and S-TSV may be used in the future to support this kind of research.

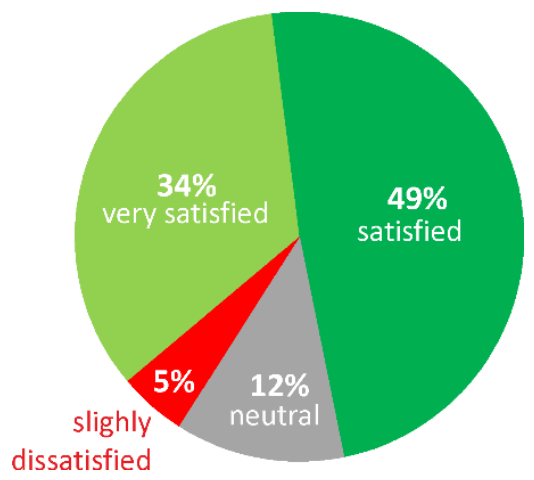

Figure 9. Overall level of satisfaction with the dwelling, as reported by study interviewees in Campinas, Brazil.

\section{Discussion}

One of the potential benefits of S-TSV is the ability to quickly survey the performance of multiple buildings; an essential step for the development of policies targeting buildings with no HVAC [10]. S-TSV can be easily applied to assess the performance of large portions of the existing building stock before and after any legislation is enforced, providing a means to monitor performance pre and post policy implementation. This sort of monitoring supports the acceptance of new legislation, as those with poor empirical support are easily criticized by the scientific community [6] and also by various stakeholders defending their particular interests regarding the built environment. The population, in particular, may adopt a sceptical attitude towards regulations with no empirical grounding, as exemplified by an unsolicited statement offered by one of the interviewees during the present survey (and recorded by the interviewer). The interviewee described his frustration with the introduction of building energy labels for dwellings in Brazil, as "there are so many important problems and the government wastes time and resources with these useless things". Empirical data, as presented in this paper, can be an important tool to raise awareness on the magnitude of problems faced by developing countries regarding the indoor quality of its built environment, 
highlighting implications for health, productivity and well-being, and consequently engaging multiple stakeholders in the policy making process.

S-TSV is a clear metric, providing information that is likely to be understood by most stakeholders in the policymaking process. The value of simplicity should not be underestimated, as people often face difficulties translating frequency-based results (e.g. 700 degree-hours of discomfort over the year) into meaningful information (e.g. is it a good or a bad performance? Is it acceptable?).

S-TSV can be a valuable tool for investigating relationships between thermal comfort and other variables relevant to energy and thermal performance. Future studies may address the relationship between S-TSV and other factors, such as:

- Dwelling operation (as illustrated in this paper by the relationship between S-TSV and stated typical behaviour for windows operation),

- Personal habits (as illustrated here by data comparing typical footwear worn indoors and S-TSV),

- Socio-economic variables (as illustrated here by data comparing income and S-TSV response),

- $\quad$ HVAC purchase intentions or/and actual purchase.

Variations in S-TSV among occupants of the same dwelling may cast light on variations in thermal comfort within the same environment and assist the identification of personal factors responsible for such variation. Thermal response varies significantly between subjects even in well controlled experiments, so the same level of variation can be also expected regarding the S-TSV of different subjects living in the same dwelling. Variation of S-TSV among subjects in the same dwelling becomes a central topic for future studies using this metric, possibly leading to the calculation of a mean S-TSV.

Previous studies have demonstrated the high uncertainty in energy performance due to operation in buildings with HVAC [163-166]. The same applies for S-TSV, where variations in results for identical dwellings (e.g. social housing or flats), may be driven by user behaviour and control. Variations in S-TSV among identical dwellings may cast light on the role of operation in the thermal performance of buildings with no HVAC. Methodological aspects regarding S-TSV data collection and analysis can also be further investigated, such as the variability on answers depending on the season in which the survey is conducted. Consistency between the responses of each interviewee could also be further scrutinized using suitable control questions and/or using surveys covering different timescales (days, weeks, or months rather than entire seasons).

Energy performance of buildings with no HVAC seems to be strongly influenced by operation and user behaviour, in line with extensive results obtained for buildings with HVAC. It highlights the importance of campaigns to raise awareness on adequate energy conservation practices regarding energy performance of buildings with no HVAC. Proper habits regarding window operation and footwear may achieve significant results at minimum cost, particularly when compared to expensive retrofit measures driven by energy labelling programs.

S-TSV shows potential to support socio-economic research into dwellings with no HVAC, including the implications of fuel poverty. While the lack of thermal comfort is well documented, understood and tackled in heating dominated developed countries, the lack of thermal comfort and its consequences in user's lives is not well understood and documented in buildings with no HVAC ranging across several income ranges.

In regard to the decision-making process for building upgrade, the collection of S-TSV can be combined with short-term surveys regarding TSV, particular targeting extreme weather periods, to provide broader empirical basis for this sort of study. To our knowledge, this decision-making process has not evaluated in light of the frequency 
and intensity of thermal discomfort in buildings, which would benefit from measures in short-term combined with the approach proposed in this paper.

Further studies working with larger samples could be useful to explore in depth the relationships identified in this small-scale field experiments. In Brazil, for example, a detailed census is conducted every 10 years, visiting tens of millions dwellings in the country. Four simple questions regarding S-TSV could provide a unique description of housing conditions across the country, supporting energy policy in a number of ways. Another possible development in this area is the use of mail or web-based surveys on S-TSV, which could reach larger samples at minimal cost.

S-TSV can be also applied in other types of buildings with no HVAC, such as schools, offices, shops, and industrial buildings. This performance metric can potentially be applied to outdoor areas as well, complementing detailed thermal comfort analysis currently carried out by experiments and thermal sensation votes at one specific point in time.

The use of building performance simulation to predict mean S-TSV would be extremely valuable. In principle, this could be achieved by empirical correlations between frequency-based simulation results (e.g. hours of discomfort) and field data on S-TSV based on an adequate sample of dwellings. This approach explores an analogy with thermal comfort models such as the PMV, where empirical correlations link heat balance results for the human body with thermal sensation votes from laboratory studies. The many challenges posed by this task shall be addressed by future studies.

It is important to point out that other disciplines have addressed the many challenges of understanding human ability to build an overall evaluation based on past events, experiences and sensations [167-169]. A wide range of experiments demonstrate that our overall evaluation is seldom a mere summation or average of sensations over time, and many factors affect our present perception of past experiences [170]. The peak-end effect, for example, describes the bias in overall evaluation due to the most extreme or recent experiences [171]. The validity of the peak-end effect has been demonstrated in many studies (and it may also play a role in S-TSV), but it has also been demonstrated that this effect is not always a relevant predictor [172]. Criticism regarding the peak-end effect indicate that more complex processes are involved in the construction of opinion based on past sensations [173]. This may be particularly valid in the area covered by this paper, considering the complex range of past sensations covering large timespans. It is also worth noting that many controlled studies in this field address sensations experienced over a few minutes or a few days [170,172], rather than sensations experienced over the entire year as addressed in STSV. It is also worth noticing that other psychological factors, such as the HALO effect [174-176], may play a role in the data collected regarding the S-TSV. The present paper provides a modest contribution in this area, by introducing the idea of systematic evaluation of long-term perception of thermal comfort and its use as a high-level indicator of building performance. Knowledge generated in this field can potentially contribute to the overall understanding of the relation between time series and overall long-term perception of subjects. Further studies are required to investigate the role of peak-end and similar processes identified in other disciplines in users' S-TSV responses. The comparison between TSV data collected over time and the S-TSV could cast light on this matter, demonstrating how users weight their thermal sensations to provide a recollected vote.

\section{Conclusions}

This paper describes a novel performance indicator to assess energy performance of dwellings with no HVAC, the Seasonal Thermal Sensation Vote. This indicator was used in a small field study in order to test its capabilities and 
deficiencies. The main conclusions of this paper are summarized below (considering the assumptions adopted in this work which is solely focused on buildings with no HVAC):

- Seasonal Thermal Sensation Vote is a straightforward and cost-effective indicator of the energy performance of buildings over long timespans, which is more likely to be understood from the perspective of non-experts than other indicators.

- Seasonal Thermal Sensation Vote for summer and winter, during daytime and night time provides a comprehensive understanding of energy performance variations over the year.

- Seasonal Thermal Sensation Vote data in combination with control questions can be used to unveil complex relations between thermal comfort, building operation and socio-economic variables.

This paper refrains from recollecting results of the field study in the conclusion section. Field study results in this paper are seen as means to demonstrate the capabilities of this novel performance indicator rather than core results of this research. Results using the Seasonal Thermal Sensation Vote in the field survey show promising investigation areas for the understanding of energy performance in dwellings with no HVAC, raising a number of questions to be further investigated by future studies. The contribution of this paper is methodological and the interesting results of the field study are just a brief demonstration of the capabilities of the proposed performance indicator.

\section{Acknowledgements}

This work was partially supported by the Coordenação de Aperfeicoamento de Pessoal de Nível Superior CAPES, Brazil, through the grant BJT A034_2013.

\section{References}

[1] I.G. Hamilton, D. Shipworth, A.J. Summerfield, P. Steadman, T. Oreszczyn, R. Lowe, Uptake of energy efficiency interventions in English dwellings, Build. Res. Inf. 42 (2014) 255-275. doi:10.1080/09613218.2014.867643.

[2] L. Maruejols, D. Young, Split incentives and energy efficiency in Canadian multi-family dwellings, Energy Policy. 39 (2011) 3655-3668. doi:http://dx.doi.org/10.1016/j.enpol.2011.03.072.

[3] J.A. Clarke, C.M. Johnstone, N.J. Kelly, P.A. Strachan, P. Tuohy, The role of built environment energy efficiency in a sustainable UK energy economy, Energy Policy. 36 (2008) 4605-4609. doi:http://dx.doi.org/10.1016/j.enpol.2008.09.004.

[4] WHO, Housing, energy and thermal comfort: a review of 10 countries within the WHO European Region, (2007).

[5] L. Murphy, The influence of the Energy Performance Certificate: The Dutch case, Energy Policy. 67 (2014) 664-672. doi:http://dx.doi.org/10.1016/j.enpol.2013.11.054.

[6] L. Murphy, F. Meijer, H. Visscher, A qualitative evaluation of policy instruments used to improve energy performance of existing private dwellings in the Netherlands, Energy Policy. 45 (2012) 459-468. doi:http://dx.doi.org/10.1016/j.enpol.2012.02.056.

[7] A. Schaffrin, N. Reibling, Household energy and climate mitigation policies: Investigating energy practices in the housing sector, Energy Policy. 77 (2015) 1-10. doi:http://dx.doi.org/10.1016/j.enpol.2014.12.002.

[8] L. Schipper, Residential energy use and conservation in Sweden, Energy Build. 6 (1984) 15-38. doi:http://dx.doi.org/10.1016/0378-7788(84)90005-7.

[9] J. Yearwood Travezan, R. Harmsen, G. van Toledo, Policy analysis for energy efficiency in the built environment in Spain, Energy Policy. $61 \quad$ (2013) 317-326. doi:http://dx.doi.org/10.1016/j.enpol.2013.05.096.

[10] L. Murphy, The policy instruments of European front-runners: effective for saving energy in existing dwellings?, Energy Effic. 7 (2014) 285-301. doi:10.1007/s12053-013-9224-8.

[11] R. Ramírez-Villegas, O. Eriksson, T. Olofsson, Assessment of renovation measures for a dwelling area Impacts on energy efficiency and building certification, Build. Environ. 97 (2016) 26-33. doi:http://dx.doi.org/10.1016/j.buildenv.2015.12.012. 
[12] F. Rogan, C.J. Cahill, H.E. Daly, D. Dineen, J.P. Deane, C. Heaps, M. Welsch, M. Howells, M. Bazilian, B.P. Ó Gallachóir, LEAPs and bounds - an energy demand and constraint optimised model of the Irish energy system, Energy Effic. 7 (2014) 441-466. doi:10.1007/s12053-013-9231-9.

[13] D. Majcen, L. Itard, H. Visscher, Actual heating energy savings in thermally renovated Dutch dwellings, Energy Policy. 97 (2016) 82-92. doi:http://dx.doi.org/10.1016/j.enpol.2016.07.015.

[14] W. Pan, H. Garmston, Compliance with building energy regulations for new-build dwellings, Energy. 48 (2012) 11-22. doi:http://dx.doi.org/10.1016/j.energy.2012.06.048.

[15] J.A. Clarke, C.M. Johnstone, J.M. Kim, P.G. Tuohy, Energy, carbon and cost performance of building stocks: upgrade analysis, energy labelling and national policy development, Adv. Build. Energy Res. 3 (2009) 1-20. doi:10.3763/aber.2009.0301.

[16] P. Wyatt, A dwelling-level investigation into the physical and socio-economic drivers of domestic energy

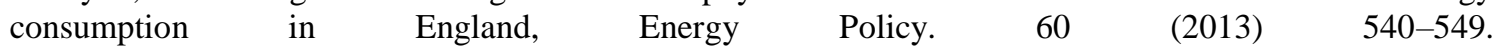
doi:http://dx.doi.org/10.1016/j.enpol.2013.05.037.

[17] N.H. Sandberg, H. Bergsdal, H. Brattebø, Historical energy analysis of the Norwegian dwelling stock, Build. Res. Inf. 39 (2011) 1-15. doi:10.1080/09613218.2010.528186.

[18] M.K. Nematchoua, R. Tchinda, P. Ricciardi, N. Djongyang, A field study on thermal comfort in naturallyventilated buildings located in the equatorial climatic region of Cameroon, Renew. Sustain. Energy Rev. 39 (2014) 381-393. doi:http://dx.doi.org/10.1016/j.rser.2014.07.010.

[19] M.K. Nematchoua, R. Tchinda, J.A. Orosa, Adaptation and comparative study of thermal comfort in naturally ventilated classrooms and buildings in the wet tropical zones, Energy Build. 85 (2014) 321-328. doi:http://dx.doi.org/10.1016/j.enbuild.2014.09.029.

[20] Y. Zhang, J. Wang, H. Chen, J. Zhang, Q. Meng, Thermal comfort in naturally ventilated buildings in hothumid area of China, Build. Environ. 45 (2010) 2562-2570. doi:http://dx.doi.org/10.1016/j.buildenv.2010.05.024.

[21] Z. Wang, L. Zhang, J. Zhao, Y. He, Thermal comfort for naturally ventilated residential buildings in Harbin, Energy Build. 42 (2010) 2406-2415. doi:10.1016/j.enbuild.2010.08.010.

[22] S. Kumar, J. Mathur, S. Mathur, M.K. Singh, V. Loftness, An adaptive approach to define thermal comfort zones on psychrometric chart for naturally ventilated buildings in composite climate of India, Build. Environ. 109 (2016) 135-153. doi:http://dx.doi.org/10.1016/j.buildenv.2016.09.023.

[23] Y. He, M. Liu, T. Kvan, S. Peng, An enthalpy-based energy savings estimation method targeting thermal comfort level in naturally ventilated buildings in hot-humid summer zones, Appl. Energy. 187 (2017) $717-$ 731. doi:http://dx.doi.org/10.1016/j.apenergy.2016.11.098.

[24] A.P. Melo, M. Fossati, R.S. Versage, M.J. Sorgato, V.A. Scalco, R. Lamberts, Development and analysis of a metamodel to represent the thermal behavior of naturally ventilated and artificially air-conditioned $\begin{array}{lllll}\text { residential buildings, } & \text { Energy } & \text { Build. } & 112 & \text { (2016) }\end{array}$ doi:http://dx.doi.org/10.1016/j.enbuild.2015.12.021.

[25] D.H.C. Toe, T. Kubota, Development of an adaptive thermal comfort equation for naturally ventilated buildings in hot-humid climates using ASHRAE RP-884 database, Front. Archit. Res. 2 (2013) 278-291. doi:http://dx.doi.org/10.1016/j.foar.2013.06.003.

[26] S.H. Hosseini, E. Shokry, A.J.A. Hosseini, G. Ahmadi, J.K. Calautit, Evaluation of airflow and thermal comfort in buildings ventilated with wind catchers: Simulation of conditions in Yazd City, Iran, Energy Sustain. Dev. 35 (2016) 7-24. doi:http://dx.doi.org/10.1016/j.esd.2016.09.005.

[27] K.-T. Huang, W.-P. Huang, T.-P. Lin, R.-L. Hwang, Implementation of green building specification credits for better thermal conditions in naturally ventilated school buildings, Build. Environ. 86 (2015) 141-150. doi:http://dx.doi.org/10.1016/j.buildenv.2015.01.006.

[28] H.-H. Liang, T.-P. Lin, R.-L. Hwang, Linking occupants' thermal perception and building thermal performance in naturally ventilated school buildings, Appl. Energy. 94 (2012) 355-363. doi:http://dx.doi.org/10.1016/j.apenergy.2012.02.004.

[29] S.I. ul Haq Gilani, M.H. Khan, W. Pao, Thermal comfort analysis of PMV model prediction in air conditioned and naturally ventilated buildings, Energy Procedia. 75 (2015) 1373-1379. doi:http://dx.doi.org/10.1016/j.egypro.2015.07.218.

[30] M.A. McNeil, V.E. Letschert, Modeling diffusion of electrical appliances in the residential sector, 2010.

[31] L.W. Davis, P.J. Gertler, Contribution of air conditioning adoption to future energy use under global warming, Proc. Natl. Acad. Sci. . 112 (2015) 5962-5967. doi:10.1073/pnas.1423558112.

[32] U. Berardi, A cross-country comparison of the building energy consumptions and their trends, Resour. Conserv. Recycl. 123 (2017) 230-241. doi:10.1016/j.resconrec.2016.03.014.

[33] P. Nejat, F. Jomehzadeh, M.M. Taheri, M. Gohari, M.Z. Abd. Majid, A global review of energy consumption, $\mathrm{CO} 2$ emissions and policy in the residential sector (with an overview of the top ten $\mathrm{CO} 2$ emitting countries), Renew. Sustain. Energy Rev. 43 (2015) 843-862. doi:10.1016/j.rser.2014.11.066.

[34] J. Iwaro, A. Mwasha, A review of building energy regulation and policy for energy conservation in developing countries, Energy Policy. 38 (2010) 7744-7755. doi:10.1016/j.enpol.2010.08.027. 
[35] A. Rackes, A.P. Melo, R. Lamberts, Naturally comfortable and sustainable: Informed design guidance and performance labeling for passive commercial buildings in hot climates, Appl. Energy. 174 (2016) 256-274. doi:10.1016/j.apenergy.2016.04.081.

[36] A. Mourtada, Case study on evaluation of energy building codes in emerging countries, (2016).

[37] S. Guillén-Lambea, B. Rodríguez-Soria, J.M. Marín, Comfort settings and energy demand for residential nZEB in warm climates, Appl. Energy. 202 (2017) 471-486. doi:10.1016/j.apenergy.2017.05.163.

[38] A.S. Silva, E. Ghisi, R. Lamberts, Performance evaluation of long-term thermal comfort indices in building simulation according to ASHRAE Standard 55, Build. Environ. 102 (2016) 95-115. doi:10.1016/j.buildenv.2016.03.004.

[39] ISO, 7730: Moderate thermal environments-Determination of the PMV and PPD indices and specification of the conditions for thermal comfort, (1994).

[40] ASHRAE, Standard 55-2010:“Thermal Environmental Conditions for Human Occupancy"; ASHRAE, Atlanta USA. (2010).

[41] EN, 15251: 2007 Indoor environmental parameters for assessment of energy performance of buildingsaddressing indoor air quality, thermal environment, lighting and acoustics, I. (n.d.).

[42] L. Peeters, R. de Dear, J. Hensen, W. D'haeseleer, Thermal comfort in residential buildings: Comfort values and scales for building energy simulation, Appl. Energy. $86 \quad$ (2009) 772-780. doi:10.1016/j.apenergy.2008.07.011.

[43] S. Carlucci, L. Pagliano, A. Sangalli, Statistical analysis of the ranking capability of long-term thermal discomfort indices and their adoption in optimization processes to support building design, Build. Environ. 75 (2014) 114-131. doi:https://doi.org/10.1016/j.buildenv.2013.12.017.

[44] S. Carlucci, L. Pagliano, A review of indices for the long-term evaluation of the general thermal comfort $\begin{array}{llllll}\text { conditions in } \quad \text { buildings, } & \text { Build. } & 53 & \text { (2012) }\end{array}$ doi:https://doi.org/10.1016/j.enbuild.2012.06.015.

[45] A. Ioannou, L. Itard, In-situ and real time measurements of thermal comfort and its determinants in thirty residential dwellings in the Netherlands, Energy Build. 139 (2017) 487-505. doi:10.1016/j.enbuild.2017.01.050.

[46] L. Yang, H. Yan, J.C. Lam, Thermal comfort and building energy consumption implications: A review, Appl. Energy. 115 (2014) 164-173. doi:10.1016/j.apenergy.2013.10.062.

[47] K.M. Fowler, E.M. Rauch, J.W. Henderson, A.R. Kora, Re-Assessing Green Building Performance: A Post Occupancy Evaluation of 22 GSA Buildings, Richland, 2010. doi:10.2172/1029438.

[48] H. Li, S.T. Ng, M. Skitmore, Stakeholder impact analysis during post-occupancy evaluation of green buildings - A Chinese context, Build. Environ. 128 (2018) 89-95. doi:10.1016/j.buildenv.2017.11.014.

[49] M.F. Silva, S. Maas, H.A. de Souza, A.P. Gomes, Post-occupancy evaluation of residential buildings in Luxembourg with centralized and decentralized ventilation systems, focusing on indoor air quality (IAQ). Assessment by questionnaires and physical measurements, Energy Build. 148 (2017) 119-127. doi:10.1016/j.enbuild.2017.04.049.

[50] R. V. Jones, S. Goodhew, P. de Wilde, Measured indoor temperatures, thermal comfort and overheating risk: Post-occupancy evaluation of low energy houses in the UK, Energy Procedia. 88 (2016) 714-720. doi:10.1016/j.egypro.2016.06.049.

[51] M.O. Sanni-Anibire, M.A. Hassanain, Quality assessment of student housing facilities through postoccupancy evaluation, Archit. Eng. Des. Manag. (2016) 1-14. doi:10.1080/17452007.2016.1176553.

[52] R. Lawrence, C. Keime, Bridging the gap between energy and comfort: Post-occupancy evaluation of two higher-education buildings in Sheffield, Energy Build. 130 (2016) 651-666. doi:10.1016/j.enbuild.2016.09.001.

[53] A. Tookaloo, R. Smith, Post Occupancy Evaluation in Higher Education, Procedia Eng. 118 (2015) 515521. doi:10.1016/j.proeng.2015.08.470.

[54] A. Martinez-Molina, P. Boarin, I. Tort-Ausina, J.L. Vivancos, Post-occupancy evaluation of a historic primary school in Spain: Comparing PMV, TSV and PD for teachers' and pupils' thermal comfort, Build. Environ. 117 (2017) 248-259. doi:10.1016/j.buildenv.2017.03.010.

[55] I.A. Meir, M. Schwartz, Y. Davara, Y. Garb, A window of one's own: a public office post-occupancy evaluation, Build. Res. Inf. (2018) 1-16. doi:10.1080/09613218.2018.1434366.

[56] A.E. Hashim, H. Aksah, S.Y. Said, Performance Review through Post Occupancy Audit on Refurbished Listed Public Building in Kuala Lumpur, J. ASIAN Behav. Stud. 3 (2018) 75-84. doi:10.21834/jabs.v3i7.260.

[57] A.C. Menezes, A. Cripps, D. Bouchlaghem, R. Buswell, Predicted vs. actual energy performance of nondomestic buildings: Using post-occupancy evaluation data to reduce the performance gap, Appl. Energy. 97 (2012) 355-364. doi:10.1016/j.apenergy.2011.11.075.

[58] E. Burman, D. Mumovic, J. Kimpian, Towards measurement and verification of energy performance under the framework of the European directive for energy performance of buildings, Energy. 77 (2014) 153-163. doi:10.1016/j.energy.2014.05.102. 
[59] Ö. Göçer, Y. Hua, K. Göçer, Completing the missing link in building design process: Enhancing postoccupancy evaluation method for effective feedback for building performance, Build. Environ. 89 (2015) 14-27. doi:10.1016/j.buildenv.2015.02.011.

[60] G. Middlehurst, R. Yao, L. Jiang, J. Deng, D. Clements-Croome, G. Adams, A preliminary study on postoccupancy evaluation of four office buildings in the UK based on the Analytic Hierarchy Process, Intell. Build. Int. (2018) 1-13. doi:10.1080/17508975.2018.1495607.

[61] J. Marley, M.C. Nobe, C.M. Clevenger, J.H. Banning, Participatory Post-Occupancy Evaluation (PPOE): A Method to Include Students in Evaluating Health-Promoting Attributes of a Green School, Child. Youth Environ. 25 (2015) 4-28. doi:10.7721/chilyoutenvi.25.1.0004.

[62] M.A. Hassanain, A. Iftikhar, Framework model for post-occupancy evaluation of school facilities, Struct. Surv. 33 (2015) 322-336. doi:10.1108/SS-06-2015-0029.

[63] C. Candido, J. Kim, R. de Dear, L. Thomas, BOSSA: A multidimensional post-occupancy evaluation tool, Build. Res. Inf. 44 (2016) 214-228. doi:10.1080/09613218.2015.1072298.

[64] A. Joseph, X. Quan, A.B. Keller, E. Taylor, U. Nanda, Y. Hua, Building a knowledge base for evidencebased healthcare facility design through a post-occupancy evaluation toolkit, Intell. Build. Int. 6 (2014) 155-169. doi:10.1080/17508975.2014.903163.

[65] A. Wheeler, M. Malekzadeh, Exploring the use of new school buildings through post-occupancy evaluation and participatory action research, Archit. Eng. Des. Manag. (2015) 440-456. doi:10.1080/17452007.2015.1021292.

[66] Arup, Bus methodology, (n.d.). https://www.busmethodology.org.uk/about.html (accessed October 2, 2018).

[67] J. Hulme, A. Beaumont, C. Summers, Energy Follow-up Survey 2011 - Report 7: Thermal comfort \& overheating (BRE report 287472)., 2013.

[68] R. de Dear, G. Brager, D. Cooper, Developing an adaptive model of thermal comfort and preference. Final report ASHRAE RP-884 (1997), Acedido Em. (2006) 11-24.

[69] M.. Ealiwa, A.. Taki, A.. Howarth, M.. Seden, An investigation into thermal comfort in the summer season of Ghadames, Libya, Build. Environ. 36 (2001) 231-237. doi:10.1016/S0360-1323(99)00071-2.

[70] A.S. Dili, M.A. Naseer, T.Z. Varghese, Passive environment control system of Kerala vernacular residential architecture for a comfortable indoor environment: A qualitative and quantitative analyses, Energy Build. 42 (2010) 917-927. doi:10.1016/j.enbuild.2010.01.002.

[71] Z. Wang, L. Zhang, J. Zhao, Y. He, Thermal comfort for naturally ventilated residential buildings in Harbin, Energy Build. 42 (2010) 2406-2415. doi:10.1016/j.enbuild.2010.08.010.

[72] K.A. Braun-LaTour, M.J. Grinley, E.F. Loftus, Tourist memory distortion, J. Travel Res. 44 (2006) 360367. doi:10.1177/0047287506286721.

[73] D. Wirtz, J. Kruger, C.N. Scollon, E. Diener, What to do on Spring Break? The Role of Predicted, on-Line, and Remembered Experience in Future Choice, Psychol. Sci. 14 (2003) 520-524. doi:10.1111/14679280.03455 .

[74] T. Pedersen, M. Friman, P. Kristensson, The role of predicted, on-line experienced and remembered satisfaction in current choice to use public transport services, J. Retail. Consum. Serv. 18 (2011) 471-475. doi:10.1016/j.jretconser.2011.06.013.

[75] P.E. McNall, J. Jaax, F.H. Rohles, R.G. Nevins, W. Springer, Thermal comfort (thermally neutral) conditions for three levels of activity, ASHRAE Trans. 73 (1967) 1-3.

[76] A.P. Gagge, J.A.J. Stolwijk, J.D. Hardy, Comfort and thermal sensations and associated physiological responses at various ambient temperatures, Environ. Res. 1 (1967) 1-20.

[77] F.H. Rohles, J.E. Woods, R.G. Nevins, The influence of clothing and temperature on sedentary comfort, ASHRAE Trans. 79 (1973) 71-80.

[78] F.H. Rohles, J.E. Woods, R.G. Nevins, The effect of air movement and temperature on the thermal sensations of sedentary man, ASHRAE Trans. 80 (1974) 101-119.

[79] P.E. McNall, P.W. Ryan, F.H. Rohles, R.G. Nevins, W.E. Springer, Metabolic rates at four activity levels and their relationship to thermal comfort, ASHRAE Trans. 74 (1968).

[80] P.O. Fanger, Thermal comfort. Analysis and applications in environmental engineering., Therm. Comf. Anal. Appl. Environ. Eng. (1970).

[81] F.H. Rohles Jr, Thermal sensations of sedentary man in moderate temperatures, Hum. Factors. 13 (1971) 553-560.

[82] R.J. De Dear, G.S. Brager, Thermal comfort in naturally ventilated buildings: Revisions to ASHRAE Standard 55, in: Energy Build., 2002: pp. 549-561. doi:10.1016/S0378-7788(02)00005-1.

[83] K. Mousli, G. Semprini, Thermal performances of traditional houses in dry hot arid climate and the effect of natural ventilation on thermal comfort: A case study in Damascus, Energy Procedia. 78 (2015) 28932898. doi:10.1016/j.egypro.2015.11.661.

[84] W. Song, F. Wang, F. Wei, Hybrid cooling clothing to improve thermal comfort of office workers in a hot indoor environment, Build. Environ. 100 (2016) 92-101. doi:10.1016/j.buildenv.2016.02.009. 
[85] R. Califano, A. Naddeo, P. Vink, The effect of human-mattress interface's temperature on perceived thermal comfort, Appl. Ergon. 58 (2017) 334-341. doi:10.1016/j.apergo.2016.07.012.

[86] K. Li, Y. Zhang, L. Zhao, Outdoor thermal comfort and activities in the urban residential community in a humid subtropical area of China, Energy Build. 133 (2016) 498-511. doi:10.1016/j.enbuild.2016.10.013.

[87] K.B. Velt, H.A.M. Daanen, Thermal sensation and thermal comfort in changing environments, J. Build. Eng. 10 (2017) 42-46. doi:10.1016/j.jobe.2017.02.004.

[88] Y. He, N. Li, W. Zhang, J. Peng, Overall and local thermal sensation \& comfort in air-conditioned dormitory with hot-humid climate, Build. Environ. 101 (2016) 102-109. doi:10.1016/j.buildenv.2016.02.025.

[89] S.A. Damiati, S.A. Zaki, H.B. Rijal, S. Wonorahardjo, Field study on adaptive thermal comfort in office buildings in Malaysia, Indonesia, Singapore, and Japan during hot and humid season, Build. Environ. 109 (2016) 208-223. doi:10.1016/j.buildenv.2016.09.024.

[90] R. Forgiarini Rupp, E. Ghisi, Predicting thermal comfort in office buildings in a Brazilian temperate and humid climate, Energy Build. 144 (2017) 152-166. doi:10.1016/j.enbuild.2017.03.039.

[91] S. ter Mors, J.L.M. Hensen, M.G.L.C. Loomans, A.C. Boerstra, Adaptive thermal comfort in primary school classrooms: Creating and validating PMV-based comfort charts, Build. Environ. 46 (2011) 2454-2461. doi:10.1016/j.buildenv.2011.05.025.

[92] A. Simone, S. Della Crociata, F. Martellotta, The influence of clothing distribution and local discomfort on the assessment of global thermal comfort, Build. Environ. 59 (2013) 644-653. doi:10.1016/j.buildenv.2012.10.001.

[93] H. Liu, Y. Wu, B. Li, Y. Cheng, R. Yao, Seasonal variation of thermal sensations in residential buildings in the hot summer and cold winter zone of China, Energy Build. 140 (2017) 9-18. doi:10.1016/j.enbuild.2017.01.066.

[94] M.K. Nematchoua, R. Tchinda, J.A. Orosa, Thermal comfort and energy consumption in modern versus traditional buildings in Cameroon: A questionnaire-based statistical study, Appl. Energy. 114 (2014) 687699. doi:10.1016/j.apenergy.2013.10.036.

[95] G. Katavoutas, M.N. Assimakopoulos, D.N. Asimakopoulos, On the determination of the thermal comfort conditions of a metropolitan city underground railway, Sci. Total Environ. 566-567 (2016) 877-887. doi:10.1016/j.scitotenv.2016.05.047.

[96] A.P. Melo, M.J. Sorgato, R. Lamberts, Building energy performance assessment: Comparison between ASHRAE standard 90.1 and Brazilian regulation, Energy Build. 70 (2014) 372-383. doi:10.1016/j.enbuild.2013.11.080.

[97] E.H. Borgstein, R. Lamberts, J.L.M. Hensen, Evaluating energy performance in non-domestic buildings: A review, Energy Build. 128 (2016) 734-755. doi:10.1016/j.enbuild.2016.07.018.

[98] M. Fossati, V.A. Scalco, V.C.C. Linczuk, R. Lamberts, Building energy efficiency: An overview of the Brazilian residential labeling scheme, Renew. Sustain. Energy Rev. 65 (2016) 1216-1231. doi:10.1016/j.rser.2016.06.048.

[99] M.A. Triana, R. Lamberts, P. Sassi, Characterisation of representative building typologies for social housing projects in Brazil and its energy performance, Energy Policy. 87 (2015) 524-541. doi:10.1016/j.enpol.2015.08.041.

[100] GOOGLE-MAPS, Aerial image of Barão Geraldo, Campinas, (2017). https://www.google.co.uk/maps/place/Barao+Geraldo,+Campinas+-+São+Paulo,+Brazil/@ -22.8177521,47.0773957,698m/data=!3m1!1e3!4m5!3m4!1s0x94c8c6cda09b6b9b:0x2e6baad018aa93e3!8m2!3d22.8226801!4d-47.0850446?hl=en (accessed May 1, 2017).

[101] M. Roriz, Campinas EPW file, (n.d.). http://www.labeee.ufsc.br/downloads/arquivos-climaticos/formatoepw (accessed May 1, 2017).

[102] A. Roetzel, A. Tsangrassoulis, U. Dietrich, S. Busching, A review of occupant control on natural ventilation, Renew. Sustain. Energy Rev. 14 (2010) 1001-1013. doi:10.1016/j.rser.2009.11.005.

[103] V. Fabi, R.V. Andersen, S. Corgnati, B.W. Olesen, Occupants' window opening behaviour: A literature review of factors influencing occupant behaviour and models, Build. Environ. 58 (2012) 188-198. doi:10.1016/j.buildenv.2012.07.009.

[104] R. Andersen, V. Fabi, J. Toftum, S.P. Corgnati, B.W. Olesen, Window opening behaviour modelled from measurements in Danish dwellings, Build. Environ. 69 (2013) 101-113. doi:10.1016/j.buildenv.2013.07.005.

[105] G. Iwashita, H. Akasaka, The effects of human behavior on natural ventilation rate and indoor air environment in summer — a field study in southern Japan, Energy Build. 25 (1997) 195-205. doi:10.1016/S0378-7788(96)00994-2.

[106] F. Haldi, D. Robinson, Interactions with window openings by office occupants, Build. Environ. 44 (2009) 2378-2395. doi:10.1016/j.buildenv.2009.03.025.

[107] S. Herkel, U. Knapp, J. Pfafferott, Towards a model of user behaviour regarding the manual control of windows in office buildings, Build. Environ. 43 (2008) 588-600. doi:10.1016/j.buildenv.2006.06.031.

[108] B. Jeong, J.W. Jeong, J.S. Park, Occupant behavior regarding the manual control of windows in residential 
buildings, Energy Build. 127 (2016) 206-216. doi:10.1016/j.enbuild.2016.05.097.

[109] D. Levie, Y.K. De, E.C.M.H. Oeffelen, H. Hofstetter, S.A. Janssen, M.E. Spiekman, F.G.H. Koene, Determinants of ventilation behavior in naturally ventilated dwellings : Identification and quantification of relationships, Build. Environ. 82 (2014) 388-399. doi:10.1016/j.buildenv.2014.09.008.

[110] Y. Zhang, P. Barrett, Factors influencing the occupants' window opening behaviour in a naturally ventilated office building, Build. Environ. 50 (2012) 125-134. doi:10.1016/j.buildenv.2011.10.018.

[111] A.K. Mishra, M. Ramgopal, Field studies on human thermal comfort - An overview, Build. Environ. 64 (2013) 94-106. doi:10.1016/j.buildenv.2013.02.015.

[112] S. Bodach, W. Lang, J. Hamhaber, Climate responsive building design strategies of vernacular architecture in Nepal, Energy Build. 81 (2014) 227-242. doi:10.1016/j.enbuild.2014.06.022.

[113] M. Kaviany, Principles of heat transfer, John Wiley \& Sons, 2002.

[114] T.L. Bergman, F.P. Incropera, D.P. DeWitt, A.S. Lavine, Fundamentals of heat and mass transfer, John Wiley \& Sons, 2011.

[115] O. Dessing, A.J. Jansen, C. Leihitu, D. Overhage, Experimental study of heat dissipation in indoor sports shoes, Procedia Eng. 72 (2014) 575-580. doi:10.1016/j.proeng.2014.06.099.

[116] R. Heus, E. Schols, W. van den Eijnde, Water vapour transport as a determinant of comfort in evaluating shoes, Elsevier Ergon. B. Ser. 3 (2005) 445-448. doi:10.1016/S1572-347X(05)80070-9.

[117] N.A.S. Taylor, C. Machado-Moreira, A. van den Heuvel, J. Caldwell, E.A. Taylor, M.J. Tipton, The roles of hands and feet in temperature regulation in hot and cold environments, (2009).

[118] H. Zhang, E. Arens, M. Taub, D. Dickerhoff, F. Bauman, M. Fountain, W. Pasut, D. Fannon, Y. Zhai, M. Pigman, Using footwarmers in offices for thermal comfort and energy savings, Energy Build. 104 (2015) 233-243. doi:10.1016/j.enbuild.2015.06.086.

[119] ISO/TS, 13732-2 Ergonomics of the thermal environment- Methods for assessment of human responses to contact with surfaces, Part2- Human contact with surfaces at moderate temperature, (2001).

[120] M. Luo, X. Zhou, Y. Zhu, J. Sundell, Revisiting an overlooked parameter in thermal comfort studies, the metabolic rate, Energy Build. 118 (2016) 152-159. doi:10.1016/j.enbuild.2016.02.041.

[121] M. Luo, B. Cao, W. Ji, Q. Ouyang, B. Lin, Y. Zhu, The underlying linkage between personal control and thermal comfort: Psychological or physical effects?, Energy Build. 111 (2016) 56-63. doi:10.1016/j.enbuild.2015.11.004.

[122] I.B. Mekjavic, B. Lenart, M. Vrhovec, M. Tomsic, N. Kakitsuba, N.A. Taylor, H. Oakley, Static and dynamic evaluation of biophysical properties of footwear: the Jozef Stefan Institute sweating thermal foot manikin system, DTIC Document, 2005.

[123] A. Dixit, U. Gade, A case study on human bio-heat transfer and thermal comfort within CFD, 2015. doi:10.1016/j.buildenv.2015.07.016.

[124] K. Kuklane, R. Afanasieva, O. Burmistrova, N. Bessonova, I. Holmér, Determination of heat loss from the feet and insulation of the footwear, Int. J. Occup. Saf. Ergon. 5 (1999) 465-476.

[125] J.L.M. Hensen, Literature review on thermal comfort in transient conditions, Build. Environ. 25 (1990) 309-316.

[126] C. Huizenga, Z. Hui, E. Arens, A model of human physiology and comfort for assessing complex thermal environments, Build. Environ. 36 (2001) 691-699. doi:10.1016/S0360-1323(00)00061-5.

[127] H. Zhang, E. Arens, C. Huizenga, T. Han, Thermal sensation and comfort models for non-uniform and transient environments, part III: Whole-body sensation and comfort, Build. Environ. 45 (2010) 399-410. doi:10.1016/j.buildenv.2009.06.020.

[128] D. Fiala, G. Havenith, P. Bröde, B. Kampmann, G. Jendritzky, UTCI-Fiala multi-node model of human heat transfer and temperature regulation, Int. J. Biometeorol. 56 (2012) 429-441.

[129] D. Fiala, K.J. Lomas, M. Stohrer, A computer model of human thermoregulation for a wide range of environmental conditions: the passive system, J. Appl. Physiol. 87 (1999) 1957-1972.

[130] D. Fiala, K.J. Lomas, M. Stohrer, Computer prediction of human thermoregulatory and temperature responses to a wide range of environmental conditions, Int. J. Biometeorol. 45 (2001) 143-159.

[131] K.J. Lomas, D. Fiala, M. Stohrer, First principles modeling of thermal sensation responses in steady-state and transient conditions, (2003).

[132] W.D. van Marken Lichtenbelt, A.J.H. Frijns, M.J. van Ooijen, D. Fiala, A.M. Kester, A.A. van Steenhoven, Validation of an individualised model of human thermoregulation for predicting responses to cold air, Int. J. Biometeorol. 51 (2007) 169-179.

[133] W.D. van Marken Lichtenbelt, A.J.H. Frijns, D. Fiala, F.E.M. Janssen, A.M.J. Van Ooijen, A.A. Van Steenhoven, Effect of individual characteristics on a mathematical model of human thermoregulation, J. Therm. Biol. 29 (2004) 577-581.

[134] L. Schellen, M.G.L.C. Loomans, B.R.M. Kingma, M.H. de Wit, A.J.H. Frijns, W.D. van Marken Lichtenbelt, The use of a thermophysiological model in the built environment to predict thermal sensation, Build. Environ. 59 (2013) 10-22. doi:10.1016/j.buildenv.2012.07.010.

[135] B. Legendre, O. Ricci, Measuring fuel poverty in France: Which households are the most fuel vulnerable?, 
Energy Econ. 49 (2015) 620-628. doi:10.1016/j.eneco.2015.01.022.

[136] A. Atsalis, S. Mirasgedis, C. Tourkolias, D. Diakoulaki, Fuel poverty in Greece: Quantitative analysis and implications for policy, Energy Build. 131 (2016) 87-98. doi:10.1016/j.enbuild.2016.09.025.

[137] R. Gillard, C. Snell, M. Bevan, Advancing an energy justice perspective of fuel poverty: Household vulnerability and domestic retrofit policy in the United Kingdom, Energy Res. Soc. Sci. 29 (2017) 53-61. doi:10.1016/j.erss.2017.05.012.

[138] S.G. Simoes, V. Greg?rio, J. Seixas, Mapping Fuel Poverty in Portugal, Energy Procedia. 106 (2016) 155165. doi:10.1016/j.egypro.2016.12.112.

[139] C. Sánchez-Guevara Sánchez, A. Mavrogianni, F.J. Neila González, On the minimal thermal habitability conditions in low income dwellings in Spain for a new definition of fuel poverty, Build. Environ. 114 (2017) 344-356. doi:10.1016/j.buildenv.2016.12.029.

[140] R. Mould, K.J. Baker, Documenting fuel poverty from the householders' perspective, Energy Res. Soc. Sci. (2017). doi:10.1016/j.erss.2017.06.004.

[141] K. Fabbri, Building and fuel poverty, an index to measure fuel poverty: An Italian case study, Energy. 89 (2015) 244-258. doi:10.1016/j.energy.2015.07.073.

[142] Z. Huang, X. Du, X. Yu, Home ownership and residential satisfaction: Evidence from Hangzhou, China, Habitat Int. 49 (2015) 74-83. doi:10.1016/j.habitatint.2015.05.008.

[143] M.A. Mohit, A.-K. Adel Mahfoud, Appraisal of residential satisfaction in double-storey terrace housing in Kuala Lumpur, Malaysia, Habitat Int. 49 (2015) 286-293. doi:10.1016/j.habitatint.2015.06.001.

[144] X. (Jason) Cao, How does neighborhood design affect life satisfaction? Evidence from Twin Cities, Travel Behav. Soc. 5 (2016) 68-76. doi:10.1016/j.tbs.2015.07.001.

[145] P. Xue, C.M. Mak, Z.T. Ai, A structured approach to overall environmental satisfaction in high-rise residential buildings, Energy Build. 116 (2016) 181-189. doi:10.1016/j.enbuild.2016.01.006.

[146] C. Fernández-Portero, D. Alarcón, Á. Barrios Padura, Dwelling conditions and life satisfaction of older people through residential satisfaction, J. Environ. Psychol. $49 \quad$ (2017) 1-7. doi:10.1016/j.jenvp.2016.11.003.

[147] Y. Sahraoui, S. Youssoufi, J.-C. Foltête, A comparison of in situ and GIS landscape metrics for residential satisfaction modeling, Appl. Geogr. 74 (2016) 199-210. doi:10.1016/j.apgeog.2016.07.011.

[148] W. Jiang, T. Feng, H. Timmermans, H. Li, A gap-theoretical path model of residential satisfaction and intention to move house applied to renovated historical blocks in two Chinese cities, Cities. 71 (2017) 1929. doi:10.1016/j.cities.2017.06.021.

[149] A.A. Fakere, O. Arayela, C.O. Folorunso, Nexus between the participation of residents in house design and residential satisfaction in Akure, Nigeria, Front. Archit. Res. 6 (2017) 137-148. doi:10.1016/j.foar.2017.02.003.

[150] S. Lin, Z. Li, Residential satisfaction of migrants in Wenzhou, an 'ordinary city' of China, Habitat Int. 66 (2017) 76-85. doi:10.1016/j.habitatint.2017.05.004.

[151] S.J.T. Jansen, The impact of the have-want discrepancy on residential satisfaction, J. Environ. Psychol. 40 (2014) 26-38. doi:10.1016/j.jenvp.2014.04.006.

[152] ASBRAV, Setor de Refrigeração, Ar Condicionado, Aquecimento e Ventilação projeta crescimento de $10 \%$ no país, (n.d.). http://asbrav.org.br/setor-de-refrigeracao-ar-condicionado-aquecimento-e-ventilacaoprojeta-crescimento-de-10-no-pais/ (accessed July 19, 2017).

[153] B. Givoni, Effectiveness of mass and night ventilation in lowering the indoor daytime temperatures. Part I: 1993 experimental periods, Energy Build. 28 (1998) 25-32. doi:10.1016/S0378-7788(97)00056-X.

[154] M. Santamouris, A. Sfakianaki, K. Pavlou, On the efficiency of night ventilation techniques applied to residential buildings, Energy Build. 42 (2010) 1309-1313. doi:10.1016/j.enbuild.2010.02.024.

[155] M. Santamouris, F. Allard, Natural ventilation in buildings: a design handbook, Earthscan, 1998.

[156] C. Cândido, R.J. de Dear, R. Lamberts, L. Bittencourt, Air movement acceptability limits and thermal comfort in Brazil's hot humid climate zone, Build. Environ. 45 (2010) 222-229. doi:10.1016/j.buildenv.2009.06.005.

[157] M.J. Sorgato, A.P. Melo, R. Lamberts, The effect of window opening ventilation control on residential building energy consumption, Energy Build. 133 (2016) 1-13. doi:10.1016/j.enbuild.2016.09.059.

[158] A.A. Maciel, B. Ford, R. Lamberts, Main influences on the design philosophy and knowledge basis to bioclimatic integration into architectural design — The example of best practices, Build. Environ. 42 (2007) 3762-3773. doi:10.1016/j.buildenv.2006.07.041.

[159] C. Cândido, R. de Dear, R. Lamberts, Combined thermal acceptability and air movement assessments in a hot humid climate, Build. Environ. 46 (2011) 379-385. doi:10.1016/j.buildenv.2010.07.032.

[160] ABNT, NBR 15220-3 Desempenho térmico de edificações Parte 3: Zoneamento bioclimático brasileiro e diretrizes construtivas para habitações unifamiliares de interesse social, (2005).

[161] F. Fuerst, P. McAllister, A. Nanda, P. Wyatt, Energy performance ratings and house prices in Wales: An empirical study, Energy Policy. 92 (2016) 20-33. doi:http://dx.doi.org/10.1016/j.enpol.2016.01.024.

[162] ABNT, NBR 15575-1: Edificações habitacionais — Desempenho Parte 1: Requisitos gerais, (2013). 
[163] B. Risholt, T. Berker, Success for energy efficient renovation of dwellings-Learning from private homeowners, Energy Policy. 61 (2013) 1022-1030. doi:http://dx.doi.org/10.1016/j.enpol.2013.06.011.

[164] D. Majcen, L.C.M. Itard, H. Visscher, Theoretical vs. actual energy consumption of labelled dwellings in the Netherlands: Discrepancies and policy implications, Energy Policy. 54 (2013) 125-136. doi:http://dx.doi.org/10.1016/j.enpol.2012.11.008.

[165] F. Belaild, Understanding the spectrum of domestic energy consumption: Empirical evidence from France, Energy Policy. 92 (2016) 220-233. doi:http://dx.doi.org/10.1016/j.enpol.2016.02.015.

[166] G. Flett, N. Kelly, An occupant-differentiated, higher-order Markov Chain method for prediction of domestic occupancy, Energy Build. 125 (2016) 219-230. doi:10.1016/j.enbuild.2016.05.015.

[167] C. Varey, D. Kahneman, Experiences extended across time: Evaluation of moments and episodes, J. Behav. Decis. Mak. 5 (1992) 169-185.

[168] D. Ariely, G. Zauberman, On the making of an experience: The effects of breaking and combining experiences on their overall evaluation, J. Behav. Decis. Mak. 13 (2000) 219.

[169] N.V. Montgomery, H.R. Unnava, Temporal Sequence Effects: A Memory Framework, J. Consum. Res. 36 (2009) 83-92. http://dx.doi.org/10.1086/595278.

[170] D. Ariely, Z. Carmon, Gestalt characteristics of experiences: the defining features of summarized events, J. Behav. Decis. Mak. 13 (2000) 191.

[171] D. Kahneman, B.L. Fredrickson, C.A. Schreiber, D.A. Redelmeier, When more pain is preferred to less: Adding a better end, Psychol. Sci. 4 (1993) 401-405.

[172] S. Kemp, C.D.B. Burt, L. Furneaux, A test of the peak-end rule with extended autobiographical events, Mem. Cognit. 36 (2008) 132-138.

[173] G.F. Loewenstein, D. Prelec, Preferences for sequences of outcomes., Psychol. Rev. 100 (1993) 91.

[174] H. Juslén, A. Tenner, Mechanisms involved in enhancing human performance by changing the lighting in the industrial workplace, Int. J. Ind. Ergon. 35 (2005) 843-855. doi:10.1016/j.ergon.2005.03.002.

[175] J.H.K. Lai, Influence of personal attributes on perception of residential facilities management services, Facilities. 32 (2014) 509-521. doi:10.1108/F-05-2012-0036.

[176] R.E. Nisbett, T.D. Wilson, The Halo Effect: Evidence for Unconscious Alteration of Judgments, J. Pers. Soc. Psychol. 35 (1977) 250-256. doi:10.1037/0022-3514.35.4.250. 